Article

\title{
Critical roles of molybdate anions in enhancing capacitive and oxygen evolution behaviors of LDH@PANI nanohybrids
}

\author{
Qiang Hu ${ }^{a}$, Hua Wang a , Feifei Xiang a , Qiaoji Zheng a , Xinguo Ma b , Yu Huo a, Fengyu Xie a, \\ Chenggang $\mathrm{Xu}^{\mathrm{a}}$, Dunmin Lin a, ${ }^{\text {, J Jisong } \mathrm{Hu}} \mathrm{b}, \#$ \\ a College of Chemistry and Materials Science, Sichuan Normal University, Chengdu 610066, Sichuan, China \\ b School of Science, Hubei University of Technology, Wuhan 430068, Hubei, China
}

\section{A R T I C L E I N F O}

\section{Article history:}

Received 17 August 2020

Accepted 9 October 2020

Available online 22 November 2020

\section{Keywords:}

Layered hydroxide LDH

PANI

$\mathrm{MoO}_{4}{ }^{2-}$

Intercalated hierarchical structures

Supercapaterry

Electrocatalyst

\begin{abstract}
A B S T R A C T
Low-overpotential layered hydroxides (LDHs) with high theoretical capacity are promising electrodes for supercapaterry and oxygen evolution reaction; however, the low electronic conductivity and insufficient active sites of bulk LDHs increase the internal resistance and reduce the capacity and oxygen-production efficiency of electrodes. Herein, we prepared a polyaniline-coated $\mathrm{Ni}$ Co-layered double hydroxide intercalated with $\mathrm{MoO}_{4}{ }^{2-}$ (M-LDH@PANI) composite electrode using a two-step method. As the amount of $\mathrm{MoO}_{4}{ }^{2-}$ in the $\mathrm{LDH}$ increases, acicular microspheres steadily evolve into flaky microspheres with a high surface area, providing more active electrochemical sites. Moreover, the amorphous PANI coating of M-LDH boosts the electronic conductivity of the composite electrode. Accordingly, the M-LDH@PANI at an appropriate level of $\mathrm{MoO}_{4}{ }^{2-}$ exhibits significantly enhanced energy storage and catalytic performance. Experimental analyses and theoretical calculations reveal that a small amount of $\mathrm{MoO}_{4}{ }^{2-}$ is conducive to the expansion of LDH interlayer spacing, while an excessive amount of $\mathrm{MoO}_{4}{ }^{2-}$ combines with the $\mathrm{H}$ atoms of $\mathrm{LDH}$, thus competing with $\mathrm{OH}^{-}$, resulting in reduced electrochemical performance. Moreover, M-LDH flaky microspheres can efficiently modulate deprotonation energy, greatly accelerating surface redox reactions. This study provides an explanation for an unconventional mechanism, and a method for the modification of LDH-based materials for anion intercalation.
\end{abstract}

(C) 2021, Dalian Institute of Chemical Physics, Chinese Academy of Sciences. Published by Elsevier B.V. All rights reserved.

\section{Introduction}

The depletion of fossil energy has stimulated the development of electrochemical energy storage and conversion system to meet the demands of markets. Among various technologies for energy storage and conversion, supercapaterry with high power density and long cycle life and electrocatalytic water cracking technology with energy saving have lately attracted extensive interest [1,2]. However, their development is still greatly limited owing to the high-cost electrocatalysts of the oxygen evolution reaction (OER) and the low energy density of supercapaterry [3-5]. It is worth noting that the electrochemical properties of SCs and OER are closely related in terms of the selection, exploration, and design of new electrode materials $[6,7]$. Hence, in the past few years, people have been committed to develop a wide range of environmentally friendly and low-cost functional nanomaterials for high-performance supercapaterry and high-efficiency electrocatalytic water de-

\footnotetext{
* Corresponding author. Tel/Fax: +86-28-84760802; E-mail: ddmd222@sicnu.edu.cn

\# Corresponding author. E-mail: jisong.hu@yahoo.com

This work was supported by Sichuan Science and Technology Program (2018JY0447).

DOI: 10.1016/S1872-2067(20)63724-X | http://www.sciencedirect.com/science/journal/18722067 | Chin. J. Catal., Vol. 42, No. 6, June 2021
} 
composition [8-10].

Among various functional nanomaterials, considerable attention has been paid to layered double hydroxides (LDHs, designated as $\left[\mathrm{M}_{1-x} \mathrm{M}_{x}^{\prime}(\mathrm{OH})_{2}\right]^{x+} \mathrm{A}^{n-}{ }_{x / n} \cdot m \mathrm{H}_{2} \mathrm{O} ; \mathrm{M}, \mathrm{M}^{\prime}=\mathrm{Mg}, \mathrm{Zn}, \mathrm{Ni}$, $\mathrm{Co}, \mathrm{Fe}$, etc., and $\mathrm{A}^{n-}$ represents an interlayer anion) due to their high reversible redox kinetics, generally low cost and environmental sustainability $[11,12]$. It was found that LDHs consist of interlayer anions and hydroxide layers with positive charges. More recently, not only a plurality of metal ions can be introduced into the LDH layer, but also a large volume anion can be inserted into the layer to synthesize various materials [13]. Therefore, LDHs have satisfactory ion exchange capacity and a tunable composition, and can be applied on anions exchangers, catalysts, and energy storage materials. PANI is a highly conductive, amorphous, and easily prepared organic polymer. The complexes of hydroxide and PANI have been reported in many researches. For instance, $\mathrm{Hu}$ et al. [5] synthesized PANI@ZnAl-LDH nanocomposites via a hydrothermal method, which exhibits higher thermal stability, anticorrosion properties, and conductivity relative to ZnAl-LDH. Feng et al. [14] prepared PANI on the surface of $\mathrm{Co}(\mathrm{OH})_{2}$ by electrodeposition, which has a low overpotential of $50 \mathrm{mV}$ at $10 \mathrm{~mA} \mathrm{~cm}-2$ in hydrogen evolution reaction. Wu et al. [15] coated PANI and NiCo-LDH on bacterial cellulose via a novel in situ corrosion growth method, which delivers a high specific capacity of $761 \mathrm{C}$ $\mathrm{g}^{-1}$ in supercapacitors. Clearly, the combination of PANI and hydroxide can improve the overall conductivity, surface stress, and stability of the material. Nevertheless, the performance improvement of LDHs in terms of energy storage and conversion system is less significant and still require further research caused by their deficient active sites, low conductivity, and narrow layer spacing.

On the other hand, the size of layer spacing determines the catalytic activity, storage capacity, and diffusion rate of ions, and the narrow layer spacing limits the access of proton acceptors between the layers because the basal plane between the LDHs layers are also the active plane [16]. For instance, Li et al. [13] demonstrated an in situ intercalation method to expand the interlayer spacing of NiFe $\mathrm{LDH}$, which has shown a small overpotential of $210 \mathrm{mV}$ at $10 \mathrm{~mA} \mathrm{~cm}^{-2}$ in oxygen evolution reaction. Luo et al. [17] synthesized NiFe LDH nanosheets intercalated with phosphorus oxyanion via a co-precipitation method, which delivers an overpotential of $215 \mathrm{mV}$ at $10 \mathrm{~mA}$ $\mathrm{cm}^{-2}$. Wang et al. [18] prepared layered $\alpha-\mathrm{Co}(\mathrm{OH})_{2}$ with various intercalated anions, which suggests the significance of the interlayer space of LDHs for high-performance supercapacitors. Clearly, a lot of investigations on the modification strategy of LDHs have been performed, including the preparation of composite electrodes, the improvement of specific surface area and conductivity, and the expansion of interlayer spacing. These studies have made progress in the improvement of the performance of LDHs because of the optimization of test environment, preparation methods, and the types and proportions of metal atoms. Specially, it should be noted that expanding the interlayer spacing of LDHs is beneficial to the energy storage and catalysis of the material. However, to our knowledge, there are few studies on the mechanism of the improvement in the performance of LDHs. Therefore, researchers will focus on exploring the synthesis and reaction mechanism of LDHs in the future, which could help people understand more micro-knowledge and propose more valuable solutions.

Here, we propose a strategy to improve the electrochemical performance of LDH by introducing the unique stoichiometry of the $\mathrm{MoO}_{4}{ }^{2-}$ into the layers of NiCo-layered double hydroxide coated PANI (M-LDH@PANI). Density functional theory (DFT) calculations provide insights into the contribution of $\mathrm{MoO}_{4}{ }^{2-}$ incorporation to structural changes and deprotonation energy of the LDH. The novel M-LDH@PANI-0.5 shows strikingly enhanced electrochemical properties compared to the pristine LDH. A supercapaterry with M-LDH@PANI-0.5 as the positive electrode and activated carbon (AC) as the negative electrode exhibits a supernal energy density of $44.6 \mathrm{Wh} \mathrm{kg}^{-1}$ along with an improved power density ( $\left.8300.0 \mathrm{~W} \mathrm{~kg}^{-1}\right)$, and $83.9 \%$ of the initial capacity is retained after 10000 cycles at a current density of $3 \mathrm{Ag}^{-1}$.

\section{Experimental}

Treatment of Ni foam (NF): A piece of Ni foam $(2 \mathrm{~cm} \times 3 \mathrm{~cm})$ was soaked for $24 \mathrm{~h}$ with $0.05 \mathrm{M} \mathrm{HCl}$ solution in order to remove the surface oxide layer. The material was taken out and rinsed with acetone, ethanol and deionized water several times in order to remove the oil contamination, respectively. All chemical reagents are analytically pure and used without further refinement.

Synthesis of M-LDH@PANI-0.5: $2 \mathrm{mmol} \mathrm{Co}\left(\mathrm{NO}_{3}\right)_{2} \cdot 6 \mathrm{H}_{2} \mathrm{O}, 2$ mmol $\mathrm{Ni}\left(\mathrm{NO}_{3}\right)_{2} \cdot 6 \mathrm{H}_{2} \mathrm{O}, 2 x(x=0,0.1,0.3,0.5,0.7,1.0) \mathrm{mmol}$ $\mathrm{Na}_{2} \mathrm{MoO}_{4}$ and $2.9 \mathrm{~g}$ urea were dissolved in $70 \mathrm{~mL}$ of DI water under magnetic stirring to form a pink solution. The reaction solution and NF were subsequently transferred into a $100 \mathrm{~mL}$ Teflon-lined stainless-steel autoclave and kept at $110^{\circ} \mathrm{C}$ for $6 \mathrm{~h}$. After cooled to room temperature, the precursors on NF were cleaned with deionized water and ethanol several times. The resultant foam was dried at $60^{\circ} \mathrm{C}$ for $12 \mathrm{~h}$ in a vacuum oven. The obtained products were denoted as LDH, M-DLH-0.1, M-DLH-0.3, M-DLH-0.5 M-DLH-0.7 and M-DLH-1, respectively. To prepare M-LDH@PANI-0.5, $0.01 \mathrm{~mol}$ aniline and $0.05 \mathrm{~mol}$ sodium p-toluenesulfonate were put into a deposition bath (100 mL). The electrochemical deposition of the PANI was performed using the Time-dependent current density curves (IT) technology at a constant voltage of $0.8 \mathrm{~V}$ in a three-electrode system. $\mathrm{Ag} / \mathrm{AgCl}$ was used as the reference electrode, platinum foil was used as the counter electrode, and M-LDH-0.5/NF was used as the working electrode to deposit PANI with electrodeposition time of 10 min on M-LDH-0.5/NF. The material was taken out and rinsed with deionized water and ethanol several times. The resulting foam was dried at 60 ${ }^{\circ} \mathrm{C}$ for $12 \mathrm{~h}$ in a vacuum oven. The average mass loading of M-LDH@PANI-0.5 is $\sim 2.4 \mathrm{mg} \mathrm{cm}^{-2}$.

Materials Characterization: The micromorphology of the samples was observed using scanning electron microscopy (SEM, FEI-Quanta 250, USA) and transmission electron microscope (FE-TEM, GZF20, USA). The elemental analysis of the samples was characterized using a scanning electron micro- 
scope (FE-SEM, JSM-7500, Japan) equipped with corresponding energy-dispersive X-ray (EDX) elemental mapping. The specific surface area (SSA) and pore size distribution were measured via Brunauer-Emmett-Teller (BET, Micromeritics ASAP2020, USA), and the SSA and pore volumes were calculated by the multi-point BET method and the nonlocal density functional theory (NLDFT), respectively. The crystal structure of the samples was characterized through the X-ray diffraction analysis (XRD, Smart Lab, Riga ku, Japan) with $\mathrm{Cu}-K_{\alpha}(\lambda=1.540598 \AA$, Smart Lab) source (scan rate of $4^{\circ} \mathrm{min}^{-1}$ ) in the $2 \theta$ range of $10^{\circ}-80^{\circ}$. The surface element analysis of the samples was carried out by a PHI 5000 VersaProbe XPS instrument (XPS, Thermo ESCALAB 250XI, USA) and Fourier transform infrared spectrum (FTIR, NICOLET iS50, USA). The elemental composition of the sample was determined by the inductively coupled plasma mass spectrometry (ICP-MS Agilent 725, USA).

Electrochemical Characterization: Electrochemical properties of the electrodes were initially tested in a three-electrode system on an electrochemical workstation (CHI660E, Shanghai, China). The as-prepared samples $\left(1 \times 1 \mathrm{~cm}^{2}\right)$ were used directly as the working Electrodes. Galvanic charge-discharge (GCD), Cyclic voltammetry (CV) and electrochemical impedance spectroscopy (EIS) tests were conducted in $3 \mathrm{M} \mathrm{KOH}$ aqueous electrolyte using platinum $(\mathrm{Pt})$ wire as a counter electrode and $\mathrm{Hg} / \mathrm{HgO}$ as a reference electrode. Specific capacity $\left(Q_{s}, \mathrm{C} \mathrm{g}^{-1}\right)$ and areal capacity $\left(Q_{a}, \mathrm{mC} \mathrm{m}^{-2}\right)$ of the electrodes were calculated from the GCD curves using the following equations.

$$
\begin{gathered}
Q_{\mathrm{s}}=I \Delta t / \mathrm{m} \\
Q_{\mathrm{a}}=1000 I \Delta t / \mathrm{s}
\end{gathered}
$$

where $I, \Delta t, m$ and $s$ represent the current density (A), discharge time (s), mass $(\mathrm{g})$ and area $\left(\mathrm{cm}^{2}\right)$ of the electrode, respectively.

Assembly of Hybrid Supercapacitor: For two-electrode system, the negative electrode was prepared by coating active carbon on $\mathrm{Ni}$ foam (AC/NF). The AC was mixed with poly (vinylidene fluoride) binder (PTFE) and acetylene black at a weight ratio of 7:2:1 in N-methylpyrrolidone (NMP). The paste was coated onto $\mathrm{Ni}$ foam $\left(1 \times 1 \mathrm{~cm}^{2}\right)$ and dried at $60{ }^{\circ} \mathrm{C}$ for $12 \mathrm{~h}$ in a vacuum oven. Subsequently, the as-formed electrode was pressed into a film under a pressure of $10 \mathrm{MPa}$. Prior to the assembly of HSC, the masses of the positive $\left(\mathrm{m}^{+}\right)$and negative electrode materials $\left(\mathrm{m}^{-}\right)$were balanced according to charge balance theory:

$$
m_{+} / m_{-}=C-V-/ C_{+} V_{+}
$$

where $m$ is the mass, $C$ is the specific capacity, and $V$ is the voltage range for the positive $(+)$ and negative $(-)$ electrodes.

For the fabrication of HSC device, the M-LDH@PANI-0.5 (2.4 $\mathrm{mg}$ in $\left.1 \times 1 \mathrm{~cm}^{2}\right)$ and $\mathrm{AC}\left(8.6 \mathrm{mg}\right.$ in $\left.1 \times 1 \mathrm{~cm}^{2}\right)$ were used as the positive and negative electrode materials, respectively, and a piece of diaphragm was used as separator to assemble a coin cell in $3 \mathrm{M} \mathrm{KOH}$ aqueous electrolyte. Specific capacity, energy and power density of the device can be calculated from current charging/discharging curves using the equations below, respectively.

$$
\begin{gathered}
C_{s}=I \Delta t / s m \\
E=1 / 2 C V^{2} \\
P=3600 E / t
\end{gathered}
$$

where $I, \Delta t, s$ and $m$ represent the current density (A), discharge time $(\mathrm{s})$, area $\left(\mathrm{cm}^{2}\right)$ of the single electrode and total active material loading mass ( $\mathrm{g}$ ) of both electrodes, respectively.

OER measurements: The LSV, I- $t$ curves and CV and EIS of as-prepared samples were measured in $1 \mathrm{M} \mathrm{KOH}(\mathrm{pH}=13.7)$ aqueous electrolyte using platinum $(\mathrm{Pt})$ wire as a counter electrode and $\mathrm{Hg} / \mathrm{HgO}$ as a reference electrode. All the working electrodes were conducted by LSV for several times with a scan rate of $2 \mathrm{mV} \mathrm{s}^{-1}$ to obtain the polarization curves until the signals were relatively stabilized. All potentials were converted for RHE though the Nernst equation: $E_{\mathrm{RHE}}=E(\mathrm{Hg} / \mathrm{HgO})+0.198$ $+0.059 \times \mathrm{pH}$, in which $E(\mathrm{Hg} / \mathrm{HgO})$ is measured potential. The overpotential $(\eta)$ could be study by the equation:

$$
\eta=E_{\mathrm{RHE}}-1.23
$$

The electrochemical surface area (ECSA) was estimated from the double-layer capacitance $\left(C_{\mathrm{dl}}\right)$ of the nanoarrays. The $C_{\mathrm{dl}}$ was determined by cycling voltammetry scans in the potential range between 0.45 and $0.35 \mathrm{~V} v s . \mathrm{Hg} / \mathrm{HgO}$ at different scan rates of 1, 3, 5, 7, $9 \mathrm{mV} \mathrm{s}^{-1}$. The capacitive currents measured at $0.40 \mathrm{~V} v s . \mathrm{Hg} / \mathrm{HgO}$ were plotted as the function of the scan rate and the specific capacitances were obtained by the linear fitting of the plots.

\subsection{Calculation of the theoretical capacity}

The first-principles calculations were performed using the ultrasoft pseudopotentials (USP) with the exchange and correlation in the local density approximation (LDA) formalisms of density functional theory (DFT) as implemented in the CASTEP package of Materials Studio [1-3]. To describe correctly vdW interactions, a hybrid semiempirical solution from Ortmann, Bechstedt and Schmidt (OBS) scheme was given to introduce damped atom pairwise dispersion corrections of the form $\mathrm{C}_{6} \mathrm{R}^{-6}$ in the DFT formalism [4]. The dispersion-corrected total energy $E_{\text {tot }}$ is represented as

$$
E_{\text {total }}=E_{\mathrm{KS}-\mathrm{DFT}}+E_{\mathrm{vdW}}
$$

where $E_{\mathrm{KS}-\mathrm{DFT}}$ is the conventional Kohn-Sham DFT energy and $E_{\mathrm{vd} w}$ is the missing dispersion contribution. The semiempirical approach provides the best compromise between the cost of first-principles evaluation of the dispersion terms and the need to improve nonbonding interactions in the standard DFT description. The valence atomic configurations are $1 \mathrm{~s}^{1}$ for $\mathrm{H}$, $2 s^{2} 2 p^{4}$ for $0,3 s^{2}$ for $\mathrm{Mg}, 3 d^{7} 4 s^{2}$ for Co and $3 d^{8} 4 s^{2}$ for Ni respectively. A cutoff energy of $400 \mathrm{eV}$ and a Monkhorst-Pack grid of for $\mathrm{Co}_{0.5} \mathrm{Ni}_{0.5}$ - $\mathrm{LDH}$ are used [5]. All structures of bulk and surface models are fully converged with the denser meshes. Geometry optimizations were done with the self-consistent convergence accuracy of $1 \times 10^{-5} \mathrm{eV} /$ atom. The convergence criterion for the maximal force on atoms is $0.1 \mathrm{eV} / \mathrm{A}$. The maximum displacement is $5 \times 10^{-3} \AA$, and the stress is less than $0.1 \mathrm{GPa}$. In addition, a vacuum layer of $15 \AA$ is used to avoid the interaction between neighbouring slabs.

Before constructing Co0.5Nio.5-LDH, we first built Mg-LDH (the space group is R-3m, $a=0.314 \mathrm{~nm}, c=2.323 \mathrm{~nm}$ ). See the supporting file for the atomic position in the crystal cell. Subsequently, the $\mathrm{Mg}$ atoms in a $3 \times 3 \times 1 \mathrm{Mg}-\mathrm{LDH}$ supercell were 
randomly replaced by Co and $\mathrm{Ni}$ atoms, and they each account for $50 \%$ of the proportion. After geometric optimization, Co0.5Ni0.5-LDH model was obtained, in which $a=0.928 \mathrm{~nm}, c=$ $2.500 \mathrm{~nm}$. At this time, the $\mathrm{Co}-\mathrm{O}, \mathrm{Ni}-\mathrm{O}$ and $\mathrm{O}-\mathrm{H}$ bond length are $0.205,0.203$ and $0.097 \mathrm{~nm}$, respectively. The distance between two adjacent plates (interlayer spacing) is $0.761 \mathrm{~nm}$, where result corresponds to $d_{003}=0.770 \mathrm{~nm}$ in XRD. In the later calculation analysis, we use double-layer $\mathrm{Co}_{0.5} \mathrm{Ni}_{0.5}-\mathrm{LDH}$ model for calculation.

The deroprotonation energy is defined as:

$$
E_{\text {deroprotonation }}=E_{\mathrm{H} 2 \mathrm{O}}+E_{\mathrm{H}-\mathrm{vacant}}-E_{\mathrm{OH}-\text { adsorbed }}
$$

Where $E_{\mathrm{H} 20}, E_{\mathrm{H} \text {-vacant }}$ and $E_{\mathrm{OH}-a d s o r b e d}$ are the total energies of the isolated $\mathrm{H}_{2} \mathrm{O}, \mathrm{Co}_{0.5} \mathrm{Ni}_{0.5}-\mathrm{LDH}$ with an $\mathrm{H}$ atom removed and $\mathrm{Co}_{0.5} \mathrm{Ni}_{0.5}-\mathrm{LDH}$ (one $\mathrm{H}$ atom bonded with one $\mathrm{OH}^{-}$), respectively.

The OER process includes four basic steps:

$$
\begin{gathered}
\mathrm{OH}^{-}+* \rightarrow{ }^{*} \mathrm{OH}+\mathrm{e}^{-} \\
{ }^{*} \mathrm{OH}+\mathrm{OH}^{-} \rightarrow{ }^{*} \mathrm{O}+\mathrm{H}_{2} \mathrm{O}+\mathrm{e}^{-} \\
* \mathrm{O}+\mathrm{OH}^{-} \rightarrow{ }^{*} \mathrm{OOH}+\mathrm{e}^{-} \\
{ }^{*} \mathrm{OOH}+\mathrm{OH}^{-} \rightarrow{ }^{*}+\mathrm{O}_{2}+\mathrm{H}_{2} \mathrm{O}+\mathrm{e}^{-}
\end{gathered}
$$

The ${ }^{*}$ represents the catalysts slabs. For convenience, we calculated the thermochemistry of OER under alkaline condition, as follows:

$$
\begin{gathered}
\mathrm{OH}^{-}+* \rightarrow{ }^{*} \mathrm{OH}+\mathrm{e}^{-} \\
{ }^{*} \mathrm{OH}+\mathrm{OH}^{-} \rightarrow{ }^{*} \mathrm{O}+\mathrm{H}_{2} \mathrm{O}+\mathrm{e}^{-} \\
{ }^{*}+\mathrm{OH}^{-} \rightarrow{ }^{*} \mathrm{OOH}+\mathrm{e}^{-} \\
{ }^{*} \mathrm{OOH}+\mathrm{OH}^{-} \rightarrow{ }^{*}+\mathrm{O}_{2}+\mathrm{H}_{2} \mathrm{O}+\mathrm{e}^{-}
\end{gathered}
$$

The Gibbs free energy changes are calculated as follows:

$$
\begin{gathered}
\Delta G_{1}=G\left({ }^{*} \mathrm{OH}\right) \\
\Delta G_{2}=G\left({ }^{*} \mathrm{O}\right)-G\left({ }^{*} \mathrm{OH}\right) \\
\Delta G_{3}=G\left({ }^{*} \mathrm{OOH}\right)-G\left({ }^{*} \mathrm{O}\right) \\
\Delta G_{4}=4.92(\mathrm{eV})-G\left({ }^{*} \mathrm{OOH}\right)
\end{gathered}
$$

The $G$ values are calculated by:

$$
\mathrm{G}=E_{\mathrm{DFT}}+E_{\mathrm{ZPE}}-\mathrm{TS}
$$

$E_{\mathrm{DFT}}$ is the total energy from the DFT calculation. $E_{\mathrm{ZPE}}$ is the zero-point energy, $S$ is the entropy and $T$ is the temperature $(298 \mathrm{~K})$. The energy of $\mathrm{H}^{+}+\mathrm{e}^{-}$is got from the energy of $\mathrm{H}_{2}$ using the standard hydrogen electrode (SHE). The $\eta$ is calculated as follows:

$$
\eta=\max (\Delta G 1, \Delta G 2, \Delta G 3, \Delta G 4) / \mathrm{e}-1.23(\mathrm{~V})
$$

\section{Results and discussion}

\subsection{Fabrication and characterization of M-LDH@PANI}

A facile hydrothermal and electrodeposition process is employed to fabricate M-LDH@PANI. The entire process, shown in Fig. 1, is designed to be convenient and environmentally friendly. As shown in Fig. 1(a), we chose Ni foam (NF) that is open, porous, and highly conductive as the substrate. Urea is hydrolyzed in solution to form carbonic acid and $\mathrm{NH}_{3}$, which increases the $\mathrm{OH}^{-}$concentration (Fig. 1(b)). Thereafter, the $\mathrm{OH}^{-}$ anions react with the metal ions $\left(\mathrm{Co}^{2+}\right.$ and $\left.\mathrm{Ni}^{2+}\right)$ in the solution to produce nanosized phases (LDH of acicular microspheres) on the NF. Fig. 1(c) shows that the introduction of various ratios of $\mathrm{MoO}_{4}{ }^{2-}$ into the LDH (M-LDH- $\left.x ; x=0.1,0.3,0.5,0.7,1\right)$ not only increases the interlayer spacing, but also transforms their morphology into flaky microspheres owing to the lattice distor-

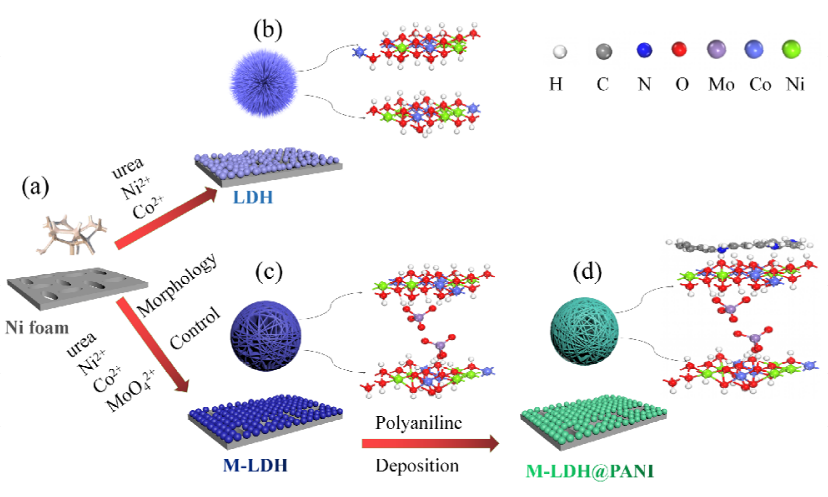

Fig. 1. Schematic representations of the two-step fabrication route for LDH, M-LDH and M-LDH@PANI architecture grown on NF.

tion of the $\mathrm{LDH}$. The surface of the $\mathrm{LDH}$ with $\mathrm{MoO}_{4}{ }^{2-}$ (M-LDH-0.5) is coated with a layer of PANI (M-LDH@PANI-0.5) to form a core-shell structure (Fig. 1(d)). The electrodeposition method enables PANI to be heteroepitaxially deposited on the surface of the LDH. After the first layer of PANI is completely covered, homoepitaxial deposition is performed to finally form the micromorphology similar to the LDH. The PANI deposited along the surface of the LDH has a strong bonding force with the LDH, leading to the change of the charge density and electron distribution state of the interface of LDH and PANI [14]. The highly conductive and amorphous PANI can reduce the intrinsic resistance of the material and increase the stress control of the core-shell structure, thereby improving the chemical stability of materials.

The microstructure and morphology of the materials is analyzed using transmission electron microscopy (TEM) and scanning electron microscopy (SEM). The LDH microspheres (Fig. S1(b)) are uniformly grown on treated NF (Fig. S1(a)) as shown in low-magnification SEM images. However, we find that these are acicular microspheres (Figs. 2(a) and S1(c)) at higher magnification. The images of the LDH and M-LDH- $x$ display that the morphology is changed after introducing $\mathrm{MoO}_{4}{ }^{2-}$ into the LDH, as shown in Figs. 2(a), 2(b), 2(d), 2(f), S1(b-h), S2(a), S2(b), S2(e), and S2(f). The increase in the amount of $\mathrm{MoO}_{4}{ }^{2-}$ transforms the morphology from acicular microspheres (LDH) to flaky microspheres (M-LDH- $x$ ). When $x=0.3$, acicular microspheres are hardly observed. It is concluded that the increase in the level of $\mathrm{MoO}_{4}{ }^{2-}$ stoichiometry in the intercalated LDH favors the growth of flaky microspheres. Figs. 2(c) and S1(i) present the images of M-LDH-0.5 after coating with a layer of PANI. It is clearly seen that there is no significant change in the surface of the flaky microspheres except for a few agglomerated nanoparticles. The plane spacing of the nanocrystals is obtained by measuring the line profile in Fig. S2(c). The lattice fringes with the interplanar spacings of $0.155 \mathrm{~nm}$ (Fig. S2(d)) and $0.770 \mathrm{~nm}$ (Fig. 2(e)) correspond to the (110) and (003) lattice planes of NiCo-LDH, respectively. However, we only detected the presence of (009) and (110) lattice planes in the HR-TEM images of M-LDH-0.5, as shown in Figs. 2(g) and S2 $(\mathrm{g})$. The (003) lattice plane corresponding to the layer spac- 


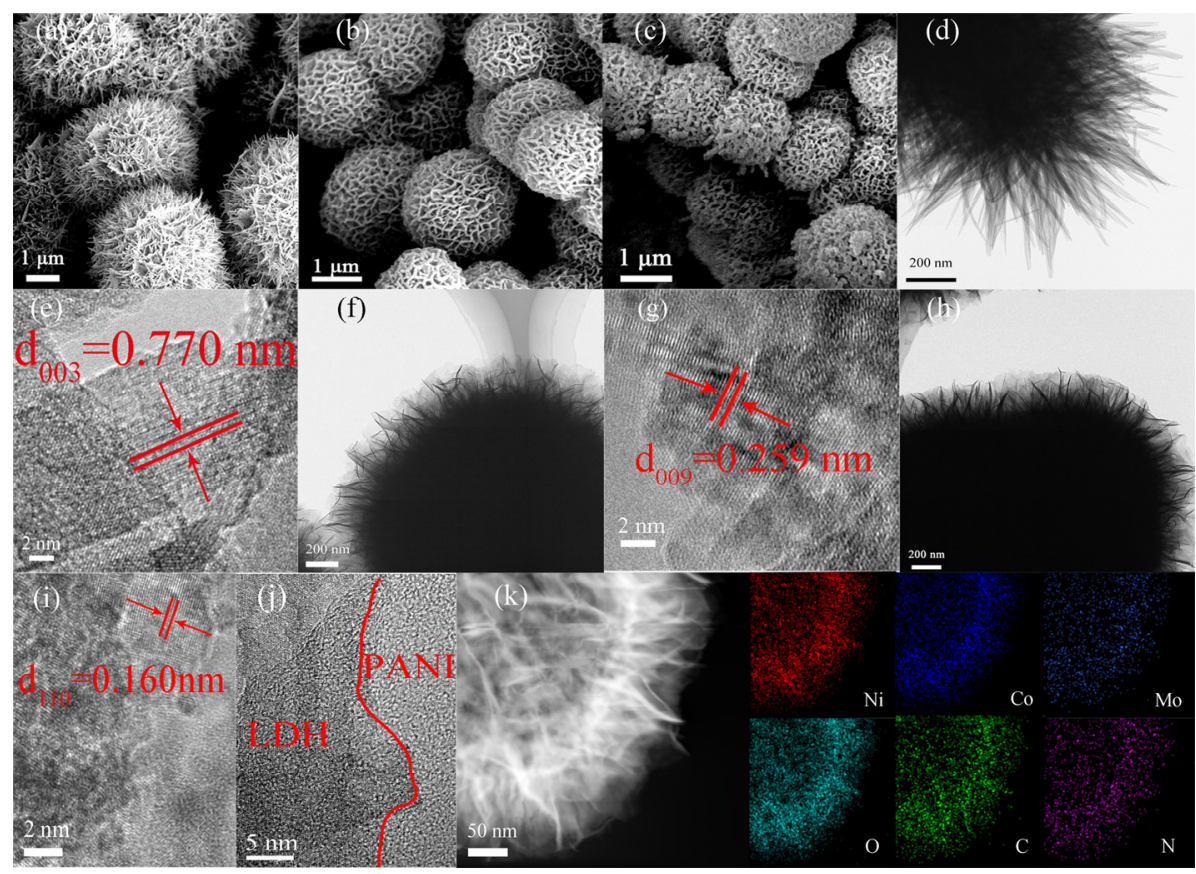

Fig. 2. (a-c) SEM images of LDH, M-LDH-0.5 and M-LDH@PANI-0.5; (d,e) TEM and HRTEM images of LDH; (f,g) TEM and HRTEM images of M-LDH-0.5; (h-j) TEM and HRTEM images of M-LDH@PANI-0.5; (k) The corresponding element mappings images of M-LDH@PANI-0.5.

ing of LDH does not appear, and will be discussed in the XRD analysis section. Besides, it can be clearly seen that $\mathrm{Ni}, \mathrm{Co}, \mathrm{O}$, and Mo elements are distributed in the M-LDH-0.5 from the transmission mapping images (Fig. S2(h)), revealing the successful introduction of $\mathrm{MoO}_{4}{ }^{2-}$ into the $\mathrm{LDH}$. The TEM images of M-LDH@PANI-0.5 (Figs. 2(h) and S2(i)) still show some flaky microspheres. Nevertheless, the high-resolution TEM (HRTEM) images of the edge area of M-LDH@PANI-0.5 (Fig. 2(j)) verifies that the M-LDH-0.5 nanosheet is well encapsulated by the PANI layer with a thickness of 3-7 $\mathrm{nm}$. Similarly, the lattice fringes with the interplanar spacings of $0.259 \mathrm{~nm}$ (Fig. S2(j)) and 0.160 nm (Fig. 2(i)) correspond to the (009) and (110) lattice planes of M-LDH@PANI-0.5, respectively. The distribution of Ni, Co, 0 , Mo, C, and N elements for M-LDH@PANI-0.5 (Fig. 2(k)) further confirm that PANI is effectively coated on the surface of M-LDH-0.5. Furthermore, the annular spots detected in the selective area electron diffraction (SAED) mode confirm the polycrystalline behavior of M-LDH@PANI-0.5, as revealed in Fig. S2(k).

The crystal structure of M-LDH is depicted in Fig. 3(a). During the preparation of $\mathrm{M}-\mathrm{LDH}, \mathrm{Ni}^{2+}$ and $\mathrm{Co}^{2+}$ with a molar ratio of 1 are hydrolyzed using the stepwise thermal decomposition of urea in the presence of $\mathrm{MoO}_{4}{ }^{2-}$. In an alkaline environment, $\mathrm{MoO}_{4}{ }^{2-}$ do not polymerize, so the negatively charged $\mathrm{MoO}_{4}{ }^{2-}$ are trapped in the channels of LDH without any issues [19]. The nominal formula of M-LDH-0.5 is determined to be $\mathrm{Ni}_{1} \mathrm{Co}_{1}(\mathrm{OH})_{2}\left(\mathrm{MoO}_{4}{ }^{2-}\right)_{0.3}\left(\mathrm{H}_{2} \mathrm{O}\right)_{x}$ based on inductively coupled plasma (ICP) analysis (Table S1). We first explored the structure of the prepared samples through X-ray diffraction (XRD). The intensity of the XRD peaks of the samples in Fig. 3(b) is rather low, indicating that they have a low degree of crystallinity. From the embedded pattern, $\beta$-phase NiCo-LDH (JCPDS card no. 14-0191) can be indexed in terms of diffraction peaks.
LDH with a smaller volume is prone to scattering, and some adjacent diffraction peaks are superimposed due to the broadening of the diffraction peaks, eventually forming a bulge. With the introduction of $\mathrm{MoO}_{4}{ }^{2-}$ and the coating of PANI, it can be clearly seen that the intensities of the (009) and (110) diffraction peaks gradually increase and those of (003), (006), (015), (018), and (113) peaks disappear. The (003) and (006) lattice planes with a larger spacing are more affected by grain refinement because lattice planes with larger $d$ values are more susceptible to damage, resulting in the broadening and weakening of the lattice planes. In the small-angle diffraction pattern of M-LDH-0.5, the disappearance of the corresponding (003) diffraction peak also proves the above explanation (Fig. S3(a)). In addition, the diffraction peaks of LDH are mainly caused by the main layer plate because the anions of the interlayer are disordered, strengthening the intensity of the secondary diffraction peak of the (003) crystal plane [20]. The $2 \theta$ angle positions of the (110) diffraction peaks for the seven LDH samples (Fig. 3 (c)) shift by a small degree. The reason is that a small amount of $\mathrm{MoO}_{4}{ }^{2-}$ may have been embedded into the (110) crystal plane, causing interplanar spacing to increase, which is consistent with the TEM results. The obtained samples are further characterized via Fourier transform infrared (FTIR) spectroscopy (Fig. 3(d)). The peaks located at 749, 1160, and $1310 \mathrm{~cm}^{-1}$ are related to the $\mathrm{C}-\mathrm{N}$ tensile vibration and $\mathrm{C}-\mathrm{H}$ in-plane bending of aromatic conjugation. The peak at $1490 \mathrm{~cm}^{-1}$ corresponds to the $\mathrm{C}=\mathrm{C}$ stretching vibration of quinoid and benzenoid rings, and the peak at $1570 \mathrm{~cm}^{-1}$ is due to $\mathrm{N}-\mathrm{H}$ vibration [21-23]. The additional peak at $3670 \mathrm{~cm}^{-1}$ reveals the presence of $\beta$-phase nickel cobalt hydroxide, because the high $\mathrm{O}-\mathrm{H}$ tensile vibration frequency connotes a weak hydrogen bonding $[24,25]$. Therefore, it is concluded that NiCo-LDH should be $\beta$-phase hydroxide, which is consistent with the XRD results. 
(a)

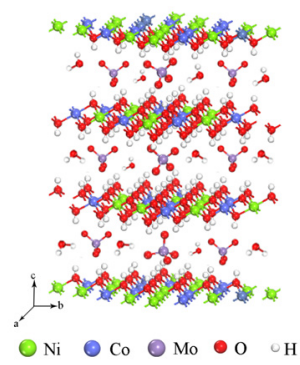

(d)
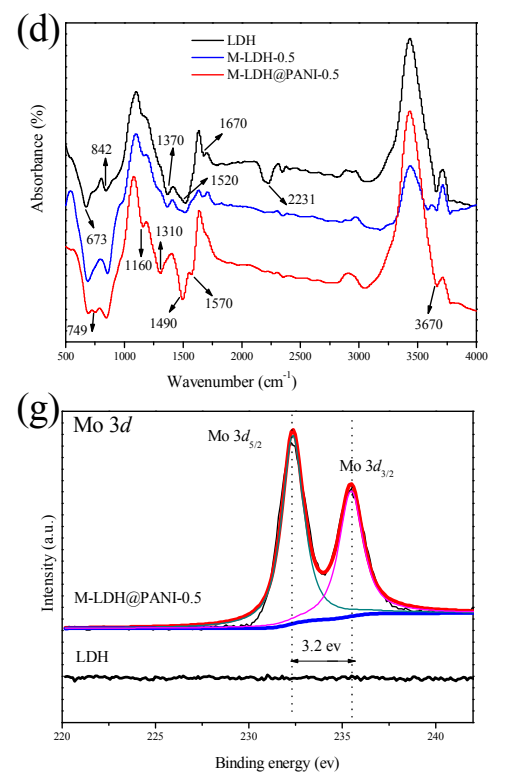
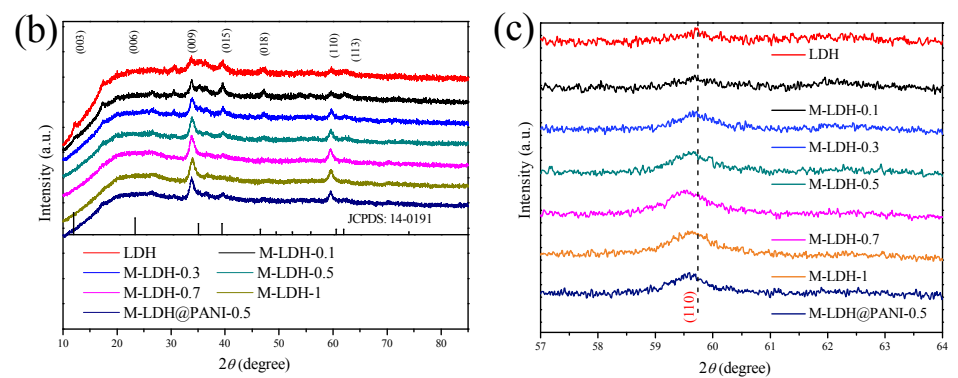

(e)

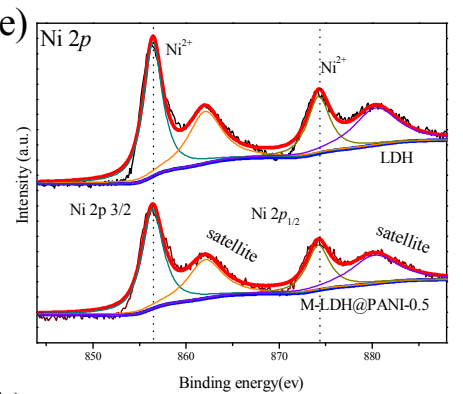

(h) 0

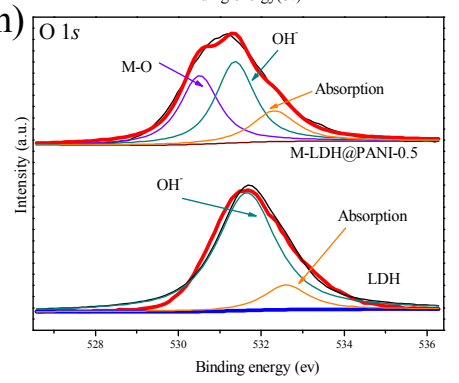

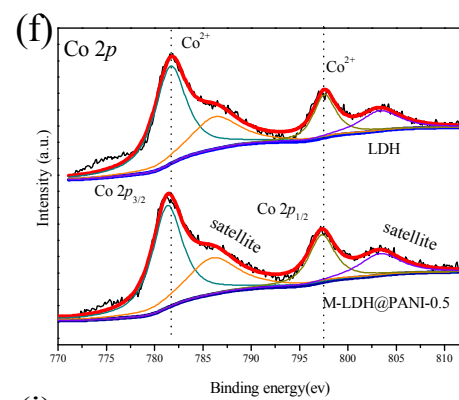

(i)

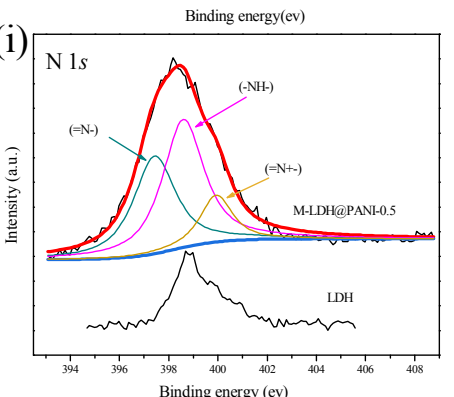

Fig. 3. (a) Schematic crystal structure of M-LDH; (b,c) XRD patterns of LDH, M-LDH- $x$ and M-LDH@PANI-0.5; (d) FTIR spectra of LDH, M-LDH-0.5 and M-LDH@PANI-0.5; (e-i) High-resolution XPS spectra of Ni 2p, Co 2p, Mo 3d, 01s and N1s in LDH and M-LDH@PANI-0.5.

The significant peak at $2231 \mathrm{~cm}^{-1}$ might be due to the stretching vibration of the cyanuric acid caused by the hydrolysis of urea $[26,27]$. The broad peak is more prominent in LDH than in M-LDH-0.5 and M-LDH@PANI-0.5, indicating that $\mathrm{MoO}_{4}{ }^{2-}$ may accelerate the decomposition of cyanuric acid during the hydrothermal process. The peak located at $1670 \mathrm{~cm}^{-1}$ is caused by the bending mode of water molecules [28]. For M-LDH-0.5, the peak is very weak, indicating that there is a very small amount of water in the material, because the introduction of $\mathrm{MoO}_{4}{ }^{2-}$ pushes out water molecules. The peak at $1370 \mathrm{~cm}^{-1}$ is primarily due to the asymmetric tensile vibration of the carbonate anion [29]. The broad peaks at 1370 and $1520 \mathrm{~cm}^{-1}$ might be due to the combination of $\mathrm{O}-\mathrm{H}$ vibration or tensile vibration of carbonate anions [30]: The peaks at 673 and $842 \mathrm{~cm}^{-1}$ are due to the vibration of the bond between oxygen and a metal.

The chemical composition of M-LDH@PANI-0.5 consists of $\mathrm{Ni}, \mathrm{Co}, \mathrm{Mo}, \mathrm{O}, \mathrm{C}$, and $\mathrm{N}$, which is studied using energy dispersive X-ray (EDX) analysis and element mapping (Fig. S3(b)). The chemical valence and elemental composition on the surfaces of LDH and M-LDH@PANI-0.5 are further studied using X-ray photoelectron spectroscopy (XPS). Fig. S4(a) displays that these samples are mainly composed of $\mathrm{Ni}, \mathrm{Co}, \mathrm{Mo}, \mathrm{O}, \mathrm{C}$, and $\mathrm{N}$, which are consistent with the EDX and transmission mapping results. The Ni $2 p$ spectra of LDH contains two satellites accompanied by two spin doublets at 874.3 and $856.4 \mathrm{eV}$, which are assigned to Ni $2 p_{1 / 2}$ and Ni $2 p_{3 / 2}$, respectively (Fig. 3(e)). The splitting width of spin-orbit doublets is $17.9 \mathrm{eV}$, proving that only $\mathrm{Ni}^{2+}$ exists [31]. Simultaneously, the introduction of $\mathrm{MoO}_{4}{ }^{2-}$ and PANI into the LDH do not result in respective changes in the positions of $\mathrm{Ni} 2 p_{1 / 2}$ and $\mathrm{Ni} 2 p_{3 / 2}$. This suggests that the bonding energy between oxygen and nickel in the hydroxide layers is not changed by the incorporation of $\mathrm{MoO}_{4}{ }^{2-}$ and PANI. The Co $2 p$ spectra of LDH and M-LDH@PANI-0.5 are provided in Fig. 3(f). The spin doublets located at 797.6 and $781.6 \mathrm{eV}$ correspond to Co $2 p_{1 / 2}$ and Co $2 p_{3 / 2}$ signals of $\mathrm{Co}^{2+}$, respectively [32]. Similarly, the introduction of $\mathrm{MoO}_{4}{ }^{2-}$ and PANI do not change the binding energy between oxygen and cobalt in the hydroxide layers. The Mo $3 d$ spectra of LDH and M-LDH@PANI-0.5 are provided in Fig. 3(g), and the spin-energy distance of $3.2 \mathrm{eV}$ in M-LDH@PANI-0.5 corresponds to $\mathrm{Mo}^{6+}$ [33]. However, the presence of Mo atom is not found in the high-resolution Mo $3 d$ spectrum of LDH. This reveals that $\mathrm{MoO}_{4}{ }^{2-}$ has been successfully introduced into the nickel cobalt hydroxides, which is consistent with XRD results. The $01 s$ region of M-LDH@PANI-0.5 in Fig. 3(h) can be divided into three peaks: the peak of metal-oxygen bonding from the $\mathrm{MoO}_{4}{ }^{2-}$ is located at $530.5 \mathrm{eV}$; the peak located at $531.4 \mathrm{eV}$ is attributed to $\mathrm{OH}^{-}$from $\mathrm{LDH}$; and the peak at $532.3 \mathrm{eV}$ is most likely due to the absorption of oxygen [34-36]. Besides, only the peaks corresponding to $\mathrm{OH}^{-}$and absorption of oxygen can 
be found in the $01 s$ region of fitting of LDH. Similarly, this is caused by the introduction of $\mathrm{MoO}_{4}{ }^{2-}$ into $\mathrm{LDH}$. As shown in Fig. 3(i), the N 1s spectra of M-LDH@PANI-0.5 can be divided into three peaks at $399.7,398.4$, and $397.3 \mathrm{eV}$, which are assigned to the nitrogen cationic amine $\left(-\mathrm{N}^{+}-\right)$, benzenoid amine $(-\mathrm{NH}-)$, and quinonoid amine (=N-) of PANI, respectively [37]. In contrast, a small amount of $\mathrm{N}$ is also detected in pure LDH owing to the nitrogen in the air [38]. Besides, the depth profiling of M-LDH- 0.5 for $\mathrm{N} 1 s$ spectra shows the content of $\mathrm{N}$ at depths of $0,5,10,15$ and $20 \mathrm{~nm}$ using Ar to etch the surface of the material (Fig. S4(b)). It can be found that the peak intensity of $\mathrm{N} 1 \mathrm{~s}$ is significantly weakened at a depth of $5 \mathrm{~nm}$, while those of $\mathrm{N} 1 \mathrm{~s}$ are basically unchanged at 10,15 and $20 \mathrm{~nm}$. This reveals that the thickness of the polyaniline on the surface of M-LDH@PANI-0.5 is 5-10 nm. From the XPS results, it may be concluded that $\mathrm{MoO}_{4}{ }^{2-}$ is inserted into $\mathrm{LDH}$, coated with a layer of PANI. The Brunauer-Emmett-Teller (BET) method is used to study the pore size and specific surface area of materials. Fig. S4(c) displays that the specific surface areas of LDH, M-LDH-0.1, M-LDH-0.5 and M-LDH-1 electrodes are calculated to be $121.4,115.4,224.8$ and $172 \mathrm{~m}^{2} \mathrm{~g}^{-1}$, respectively. Moreover, the pore size distribution of LDH, M-LDH-0.1 and M-LDH-1 show that there are mainly composed of mesopores, while M-LDH-0.5 is mainly composed of micropores and mesopores (Fig. S4(d)). The transition of acicular microspheres (LDH and M-LDH-0.1) to flaky nanosphere (M-LDH-0.5 and M-LDH-1) with the change of specific surface area could improve the diffusion kinetics of the electrolyte ions and the utilization of the material, which is expected to enhance electrochemical performance.

\subsection{Electrochemical properties of $L D H, M-L D H-x$ and M-LDH@PANI-0.5}

The electrochemical properties of the prepared samples for supercapaterry are investigated in a three-electrode cell using $3 \mathrm{M} \mathrm{KOH}$ as the aqueous electrolyte. To investigate the effect of $\mathrm{NF}$ on the performance of supercapaterry, the cyclic voltammetry (CV) curves and galvanostatic charge-discharge (GCD) curves of a pure NF electrode are included in Figs. S5(a) and (b), which are compared with M-LDH@PANI-0.5 electrodes. It can be seen from the $\mathrm{CV}$ results that the capacity of the pure NF electrode is almost negligible, which is a good indication that $\mathrm{NF}$ does not contribute to the capacity performance. A comparison of the CV curves of LDH, M-LDH- $x$ and M-LDH@PANI-0.5 electrodes is summarized in Fig. 4(a). Evidently, they have characteristic redox peaks dominated by the Faradaic redox reactions from $\mathrm{Co}(\mathrm{OH})_{2} / \mathrm{CoOOH}, \mathrm{Ni}(\mathrm{OH})_{2} / \mathrm{NiOOH}$, and $\mathrm{CoOOH} / \mathrm{CoO}_{2}$ [20]. Besides, the $\mathrm{CV}$ enclosed curve areas of the M-LDH@PANI-0.5 electrode are larger than those of all other samples, indicating higher specific capacity. The CV curves of the M-LDH@PANI-0.5 and various M-LDH- $x$ electrodes collected at different scan rates are shown in Figs. 4(b) and S6. As the scan rate increases, the $\mathrm{CV}$ curves become asymmetrical owing to the unsatisfactory electrical resistance of the electrode material [39]. To further explore the charge storage mechanism of the samples, we evaluated the relationship between cathodic peak response $\left(i_{\mathrm{p}}\right)$ and scan rate $(v)$ using the power law $\left(i_{\mathrm{p}}=\right.$ $\mathrm{a} \cdot v^{b}$ ). Typically, $b=0.5$ represents the current response of a diffusion control, and $b=1.0$ represents a surface-controlled process. Fig. 4(c) reveals that the calculated b-values for LDH, M-LDH- $x$, and M-LDH@PANI-0.5 ( $x=0.1,0.3,0.5,0.7$ and 1$)$ are in the range of $0.524-0.667$, which are closer to 0.5 , suggesting the prevailing diffusion-controlled behavior. This is consistent with the previous reports with respect to battery-type materials [40]. The GCD tests for the LDH, M-LDH-x, and M-LDH@PANI-0.5 electrodes are conducted at different current densities (Figs. 4(d) and S7(a)-(f)). The GCD curves at different current densities are almost symmetrical, indicating that the electrodes have high reversibility and fast response. The discharge time of M-LDH- $x$ increases with increased $\mathrm{MoO}_{4}{ }^{2-}$ source content until the optimal amount of $\mathrm{MoO}_{4}{ }^{2-}$ source $(x=$ 0.5 ), as shown in Fig. 4(e). However, the introduction of excess $\mathrm{MoO}_{4}{ }^{2-}$ leads to new compounds with a crystal structure of $\mathrm{H}_{2} \mathrm{MoO}_{4}$. This inhibits the reaction of $\mathrm{OH}^{-}$ions with $\mathrm{H}$ atoms during charge and discharge, resulting in reduced electrochemical performance, which will be further discussed in the DFT section. Moreover, the discharge time of M-LDH-0.5 is improved and its rate performance increases from $41 \%$ to $53 \%$ after coating with a layer of PANI. The calculated specific capacities of the LDH, M-LDH- $x$ with $x=0.1,0.3,0.5,0.7$, and 1, and M-LDH@PANI-0.5 based on GCD curves at $1 \mathrm{~A} \mathrm{~g}^{-1}$ are 331, $465,656,754,615.8,420.1$ and $864.8 \mathrm{C} \mathrm{g}^{-1}$, respectively (Fig. 4(f)). The specific capacity of LDH is increased by 2.61 times as it is converted to M-LDH@PANI-0.5. This ultra-high capacity is due to the fact that the conversion of acicular microspheres (LDH) into flaky microspheres (M-LDH@PANI-0.5) greatly increases the specific surface area, which results in a high contact area and rapid ion/electron transfer between the active material and the electrolyte. As a result, the nanostructure of M-LDH@PANI-0.5 adequately benefits from the charge contribution of Faradaic and non-Faradaic processes. Besides, the significant improvement of specific capacity is also related to the increase in interlayer spacing, conductivity, and reaction sites of $\mathrm{LDH}$, indicating that the introduction of $\mathrm{MoO}_{4}{ }^{2-}$ and the coating of PANI play key roles in improving charge-storage capacity. It is worth noting that the superior specific capacity of optimized M-LDH@PANI-0.5 is highly competitive with the previously reported LDH-based materials (Table S3). The Nyquist plots of the LDH, M-LDH-0.5, and M-LDH@PANI-0.5 electrodes consist of three parts (Fig. 4(g)). Typically, the semicircular diameter of the high frequency region represents the charge transfer resistance of the current collector materials and the electrode materials-electrolyte interface $\left(R_{c t}\right)$, and the real axis intercept is the sum of the ionic resistances of the electrolyte $\left(R_{S}\right)$. In addition, the constant-phase element (CPE) is part of the circuit test and the Warburg impedance $(W)$ is related to the diffusivity within electroactive materials and electrolyte ion diffusion length. The fitting parameters of the three electrodes are obtained using an equivalent circuit (Table S2). M-LDH@PANI-0.5 displays much smaller $R_{s}\left(0.53 \Omega \mathrm{cm}^{2}\right)$ and Rct (3.02 $\Omega \mathrm{cm}^{2}$ ) than those of the pristine LDH and M-LDH-0.5, connoting faster charge transfer and higher electrical conductivity. The Warburg factor can be calculated from 
(a)

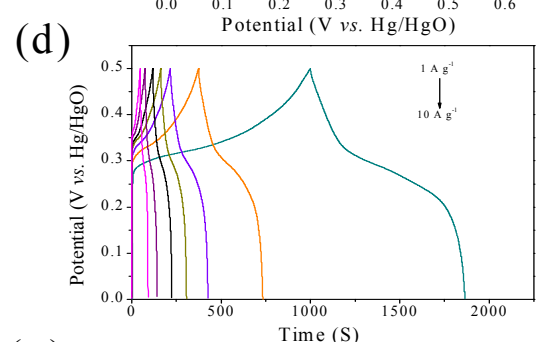

(g)
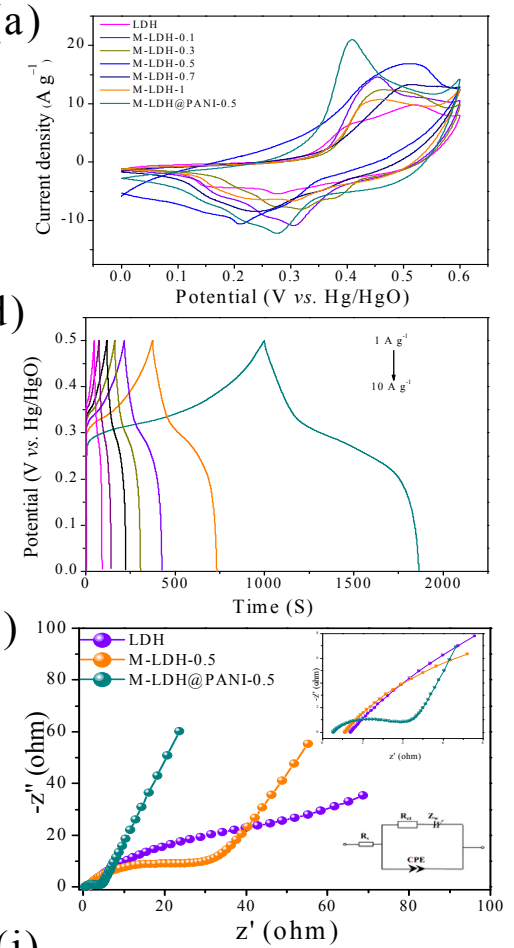

(b)

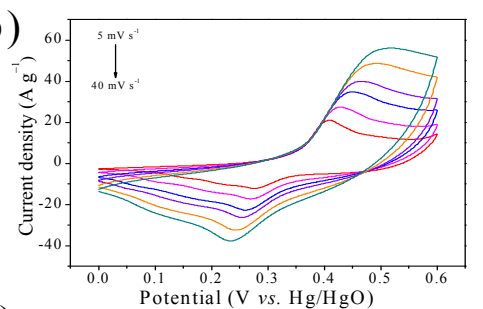

(e)

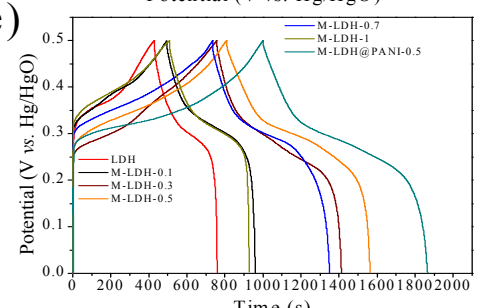

(c)

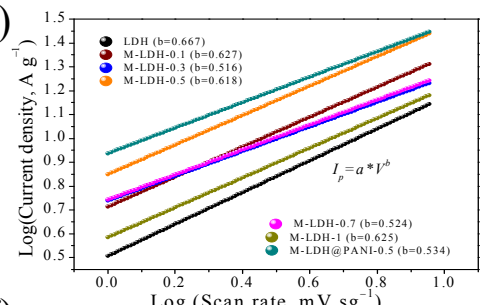

(f)

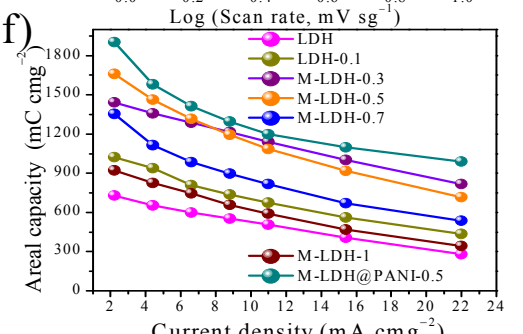
Current density ( $\mathrm{m} \mathrm{A} \mathrm{cm} \mathrm{g}^{-2}$ )

(h)
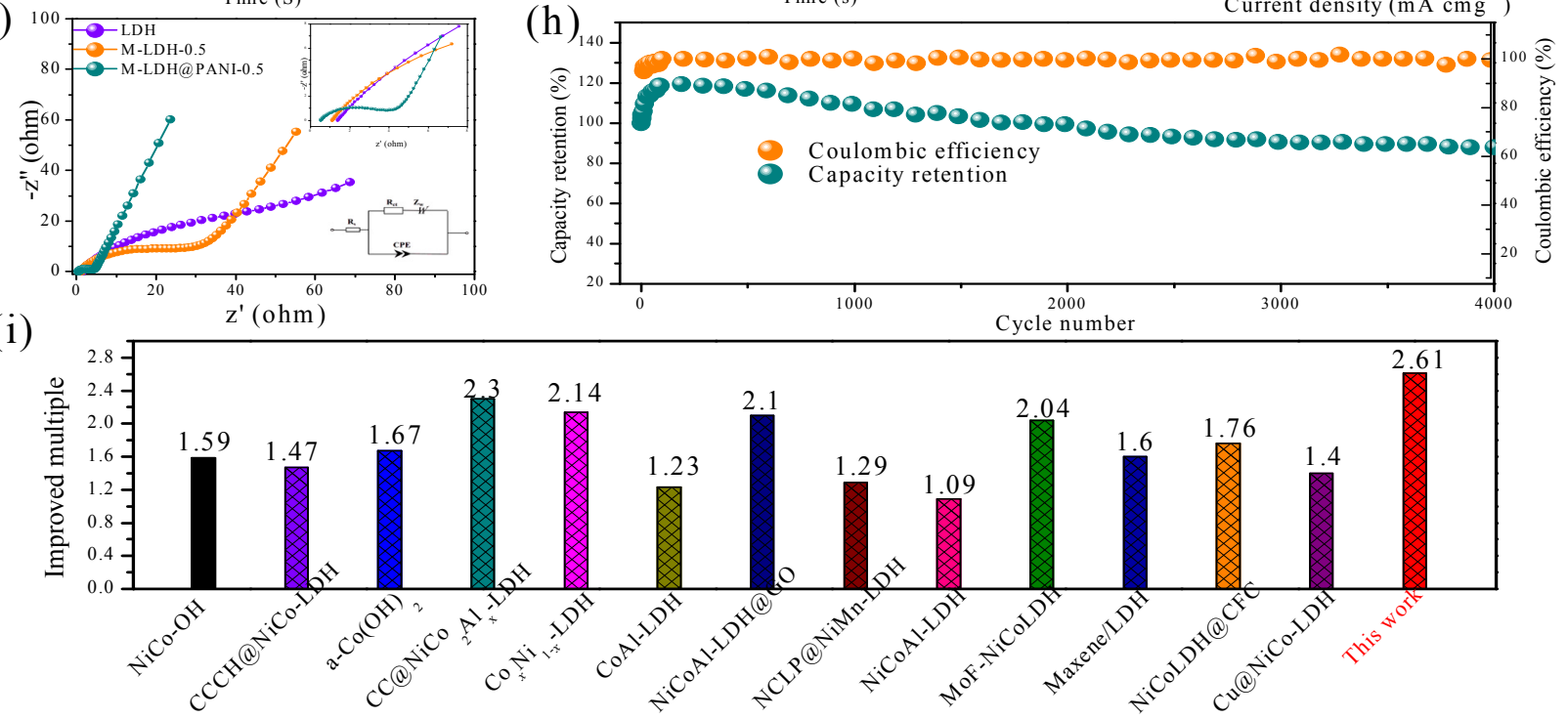

Fig. 4. (a) Comparative CV curves of LDH, M-LDH- $x$ and M-LDH@PANI-0.5 electrodes at scan rate of 5 mV s electrode at different scan rates; (c) Power law dependence of redox peak current on scan rate for LDH, M-LDH- $x$ and M-LDH@PANI-0.5 electrodes; (d) GCD curves of M-LDH@PANI-0.5 electrode at different current densities; (e) Comparative GCD curves of LDH, M-LDH- $x$ and M-LDH@PANI-0.5 electrodes at a current density of $1 \mathrm{~A} \mathrm{~g}^{-1}$; (f) Specific capacities of LDH, M-LDH- $x$ and M-LDH@PANI-0.5 electrodes as function of current density; (g) Nyquist plots of LDH, M-LDH-0.5 and M-LDH@PANI-0.5 electrodes; (h) Cycling stability of M-LDH@PANI-0.5 electrode at a current density of 5 A g-1; (i) A comparison of improvement ability of our strategy with the values of previously reported similar electrodes.

$\mathrm{Z}^{\prime}$ and angular frequency, as shown in Fig. S8. It can be seen that the introduction of $\mathrm{MoO}_{4}{ }^{2-}$ and the coating of PANI both reduce the slope of $\mathrm{LDH}$, revealing that the larger layer spacing and core-shell structure of M-LDH@PANI-0.5 provide a fast transmission path for $\mathrm{OH}^{-}$. The columbic efficiency and cycling stability of M-LDH@PANI- 0.5 electrode at a current density of 5 A g ${ }^{-1}$ are shown in Fig. 4(h). The core-shell M-LDH@PANI-0.5 electrode maintains excellent electrochemical stability of $\sim 87 \%$ after 4000 cycles. It is found that a $20 \%$ increase in specific capacity is observed during the first 200 cycles, which may be related to the electrochemical activation of the electrode material [8]. In addition, the coulombic efficiency of the M-LDH@PANI-0.5 electrode is $99.5 \%$ after 4000 cycles. The cycle stability of M-LDH@PANI-0.5 is verified by observing the SEM image after cycling measurements (Fig. S9). The image shows that the shape and structure of M-LDH@PANI-0.5 are well maintained. The conversion of acicular microspheres
(LDH) into flaky microspheres (M-LDH@PANI-0.5) greatly improves the specific capacity of the electrode after the incorporation of $\mathrm{MoO}_{4}{ }^{2-}$ and PANI. This strategy of increasing the specific capacity of LDH is compared with the previously reported methods (Fig. 4(i)) [18,20,25,29,32,34,41-47].

\subsection{DFT calculations of $L D H, M-L D H-x$}

The introduction of $\mathrm{MoO}_{4}{ }^{2-}$ into $\mathrm{LDH}$ will inevitably cause structural changes due to the tetrahedral structure and charged properties of $\mathrm{MoO}_{4}{ }^{2-}$. The calculation method, coordinate parameters, and crystal structure of $\mathrm{LDH}$ and M-LDH are shown in Fig. S10 and Table S4. Here, we first discuss the adsorption of $\mathrm{MoO}_{4}{ }^{2-}$ inside and outside the interface of $\mathrm{Co}_{0.5} \mathrm{Ni}_{0.5} \mathrm{LDH}$ (designated as $\mathrm{LDH}$ ). As shown in Figs. 5(a)-(c), when $\mathrm{MoO}_{4}{ }^{2-}$ is inside the interface of $\mathrm{LDH}$, the interlayer spacing is $0.875 \mathrm{~nm}$, which is $0.114 \mathrm{~nm}$ larger than that without $\mathrm{MoO}_{4}{ }^{2-}(0.761 \mathrm{~nm})$. 


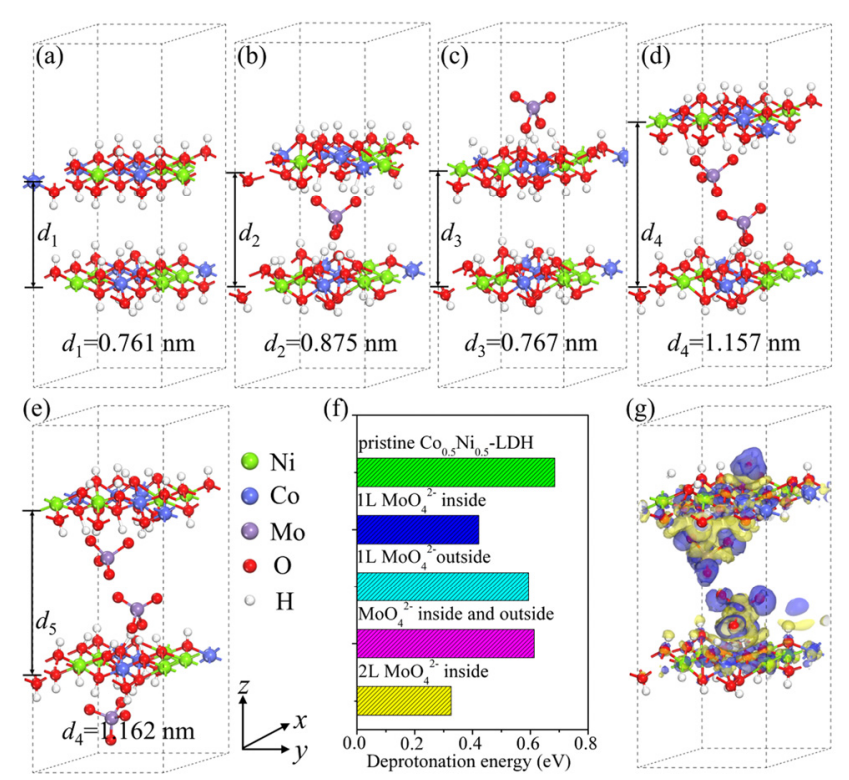

Fig. 5. (a) Side views of pristine double-layer $\mathrm{Co}_{0.5} \mathrm{Ni}_{0.5}-\mathrm{LDH} ; \mathrm{MoO}_{4}{ }^{2-}$ (b) inside and (c) outside interface of $\mathrm{Co}_{0.5} \mathrm{Ni}_{0.5}-\mathrm{LDH}$; (d) Stacked $\mathrm{MoO}_{4}{ }^{2-}$ inside interface of $\mathrm{Co}_{0.5} \mathrm{Ni}_{0.5}-\mathrm{LDH}$; (e) $\mathrm{MoO}_{4}{ }^{2-}$ inside and outside interface of $\mathrm{Co}_{0.5} \mathrm{Ni}_{0.5}-\mathrm{LDH}$; (f) The calculated deprotonation energy of pristine, one-layer $\mathrm{MoO}_{4}{ }^{2-}$ inside, one-layer $\mathrm{MoO}_{4}{ }^{2-}$ outside, $\mathrm{MoO}_{4}{ }^{2-}$ inside and outside the interface and two-layer $\mathrm{MoO}_{4}{ }^{2-}$ inside the interface of $\mathrm{Co}_{0.5} \mathrm{Ni}_{0.5}-\mathrm{LDH}$, respectively; (g) Charge density difference isosurfaces for the deprotonation process on two-layer $\mathrm{MoO}_{4}{ }^{2-}$ inside the interface of $\mathrm{Co}_{0.5} \mathrm{Ni}_{0.5}-\mathrm{LDH}$; yellow and blue areas indicate charge depletion and charge accumulation zones, respectively (isosurface value is 0.01 $\left.\mathrm{eV} / \AA^{3}\right)$.

While the $\mathrm{MoO}_{4}{ }^{2-}$ is outside the interface, the interlayer spacing only changes by $0.006 \mathrm{~nm}(0.767 \mathrm{~nm})$. Evidently, the intercalation of $\mathrm{MoO}_{4}{ }^{2-}$ is conducive to the expansion of the LDH interlayer, thus increasing its specific surface area. Comparing the total energy of $\mathrm{MoO}_{4}{ }^{2-}$ inside and outside the interface of $\mathrm{LDH}$, we find that the total energy of $\mathrm{MoO}_{4}{ }^{2-}$ inside the interface of LDH is lower (approximately $3.158 \mathrm{eV}$ ). This means that $\mathrm{MoO}_{4}{ }^{2-}$ preferentially enters the interlayer of LDH when it is added, which increases the interlayer spacing and the specific surface area of the whole morphology. In addition, we find that the deprotonation energy of $\mathrm{MoO}_{4}{ }^{2-}$ intercalated $\mathrm{LDH}$ is 0.352 $\mathrm{eV}$ lower than that of the pristine one (Fig. 5(f)), which indicates that the electrochemical performance of $\mathrm{LDH}$ with $\mathrm{MoO}_{4}{ }^{2-}$ is better. The deprotonation energy calculations for these crystal models are illustrated in Fig. S11. The increase in the amount of $\mathrm{MoO}_{4}{ }^{2-}$ inside the interface results in the stacking of $\mathrm{MoO}_{4}{ }^{2-}$. Therefore, we construct a model in which $\mathrm{MoO}_{4}{ }^{2-}$ is stacked along the $z$ direction, as shown in Fig. 5(d) after optimization. It is found that interlayer spacing increases to 1.157 $\mathrm{nm}$, which indicates that the increase in $\mathrm{MoO}_{4}{ }^{2-}$ concentration further improves interlayer spacing, leading to the formation of $\mathrm{LDH}$ with a few layers. In addition, $\mathrm{MoO}_{4}{ }^{2-}$ inside and outside interface of LDH is also modeled, as shown in Fig. 5(e). This structure corresponds to when there are excess $\mathrm{MoO}_{4}{ }^{2-}$. We can see that deprotonation energy increases significantly, but remains lower than that of a pristine one. Therefore, the inconsistencies of crystal growth in the $z$ direction owing to the en- largement of the layer spacing of M-LDH results in the changes in microscopic morphology. Charge density difference is commonly used to estimate the charge transfer between atoms. Fig. 5(g) shows the charge density difference isosurfaces for the deprotonation process on two-layer $\mathrm{MoO}_{4}{ }^{2-}$ inside the interface of LDH. The close charge exchange mainly occurs between the $\mathrm{H}$ and $\mathrm{O}$ atoms, while Mo hardly undergoes charge transfer during the deprotonation process. With the increase in $\mathrm{MoO}_{4}{ }^{2-}$ concentration, the excess $\mathrm{MoO}_{4}{ }^{2-}$ combines with the $\mathrm{H}$ atoms of LDH due to their strong electrostatic interaction, resulting in the inhibition of the reaction between the $\mathrm{OH}^{-}$and $\mathrm{H}$ atom. The results also show that the desorption energy of $\mathrm{H}$ atoms of $\mathrm{LDH}$ combined with $\mathrm{MoO}_{4}{ }^{2-}$ increases, rendering the desorption of $\mathrm{H}$ atom difficult. This means that the $\mathrm{MoO}_{4}{ }^{2-}$ in $\mathrm{LDH}$ does not contribute to the improvement of capacitance, which is consistent with previously reported literature [18]. In sum, a small amount of $\mathrm{MoO}_{4}{ }^{2-}$ is conducive to the expansion of the $\mathrm{LDH}$ interlayer spacing to improve its electrochemical performance, while an excessive amount of $\mathrm{MoO}_{4}{ }^{2-}$ will combine with the $\mathrm{H}$ atoms of $\mathrm{LDH}$ and compete with $\mathrm{OH}^{-}$, resulting in reduced electrochemical performance, which is consistent with the experimental results.

\subsection{Electrochemical performances of the fabricated hybrid supercapaterry device}

In order to evaluate the electrochemical performance of M-LDH@PANI-0.5 in practical applications, we assemble a hybrid supercapaterry device (HSC) with M-LDH@PANI-0.5 as the positive electrode and $\mathrm{AC}$ as the negative electrode in $3 \mathrm{M}$ KOH aqueous solution electrolyte with a piece of cellulose paper as the separator (Fig. 6(a)). The CV and GCD curves of AC display a typical double-layer capacitance characteristic (Figs. S12(a) and (b)), and the calculated specific capacity is $241 \mathrm{C} \mathrm{g}^{-1}$ at $1 \mathrm{~A} \mathrm{~g}^{-1}$ (Fig. S12(c)). To obtain a reasonable voltage window for the HSC, the CV curves for AC and M-LDH@PANI-0.5 are investigated in a three-electrode system with a potential window of $-1-0$ and $0-0.6 \mathrm{~V}$ at a scan rate of $5 \mathrm{mV} \mathrm{s}^{-1}$, respectively. The voltage window of the HSC may be extended to $1.6 \mathrm{~V}$ using a combination of EDLC and electrochemical capacitors, as shown in Fig. S12(d). After the device is fabricated, a series of CV and GCD tests are performed at different potential areas to avoid damage at high voltages. Fig. 6(b) explores the CV curves of the HSC at a stable scan rate of $10 \mathrm{mV} \mathrm{s}^{-1}$ under different potential windows from $0-1.2 \mathrm{~V}$ to $0-1.6 \mathrm{~V}$. The lack of evolution of hydrogen/oxygen at high potential scans (0-1.6 V) indicates that the optimal operating potential window for the HSC can reach 1.6 V. Fig. 6(c) shows the GCD curves with a current density of $1 \mathrm{~A} \mathrm{~g}^{-1}$ at different voltage windows. It is expected that when the voltage window is greater than $1.6 \mathrm{~V}$, the GCD curves will become less symmetrical, indicating that the maximum operating voltage of the HSC is 1.6 V. Fig. 6(d) exhibits the $\mathrm{CV}$ curves at different scan rates. As the scan rate increases, the shape of the $\mathrm{CV}$ curves remains the same, indicating superior rate performance due to the fast ion and electron transport kinetics of the electrode materials. It can be seen from the GCD curves (Fig. 6(e)) at different current densities from 1 to $10 \mathrm{~A}$ 
(a)

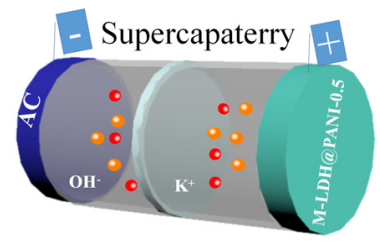

(d)

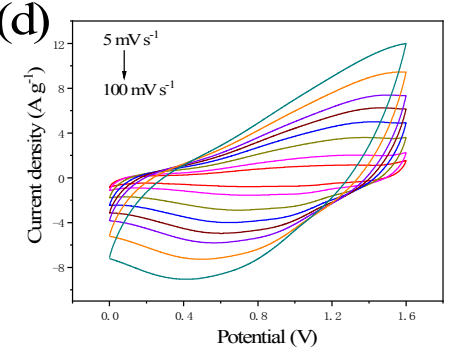

(g)

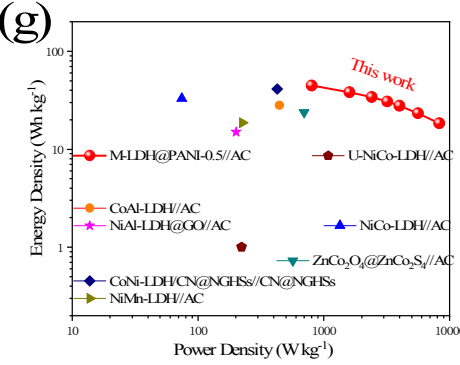

(b)

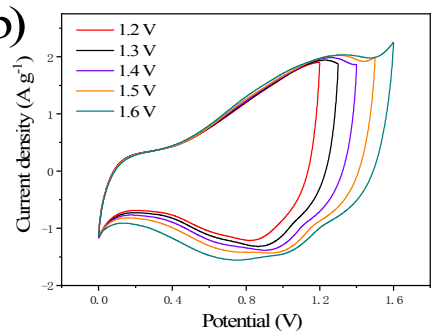

(e)

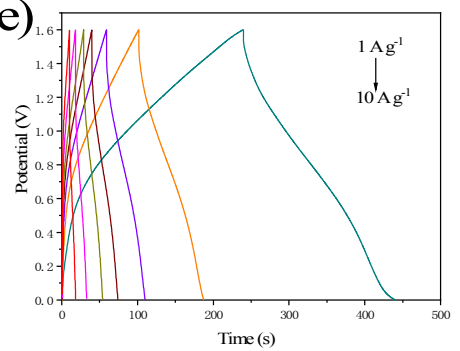

(c)

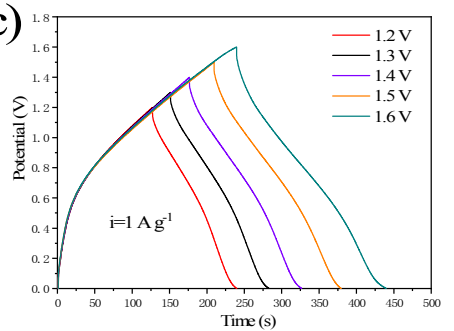

(f)

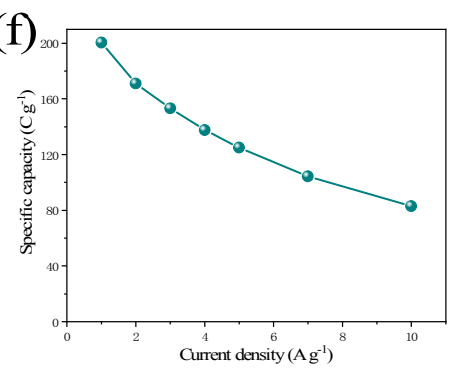

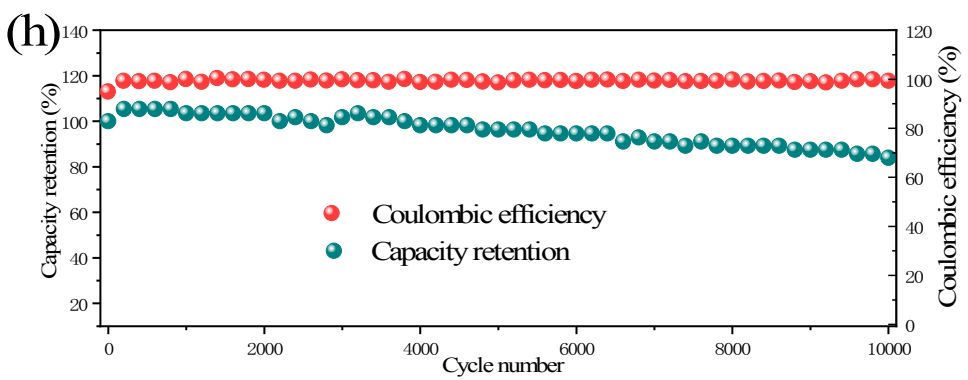

Fig. 6. (a) Schematic of device fabrication; (b) Cyclic voltammetry curves of HSC at various voltage windows at $10 \mathrm{mV} \mathrm{s}^{-1}$; (c) GCD curves of HSC at various voltage windows at $1 \mathrm{~A} \mathrm{~g}^{-1}$; (d) CV curves of HSC at different scan rates; (e) GCD curves of HSC device at different current densities; (f) Specific capacity of HSC device at different current densities; (g) Comparison of the Ragone plots of the present and reported devices; and (h) cycling stability at a current density of $3 \mathrm{Ag}^{-1}$.

$\mathrm{g}^{-1}$ that the charge and discharge times of the devices are almost equal, suggesting that the coulombic efficiency and charge storage balance are excellent. According to the GCD curves, specific capacity is shown in Fig. 6(f). The HSC displays high specific capacities of 200.5 and $83 \mathrm{C} \mathrm{g}^{-1}$ at the discharge current densities of 1 and $10 \mathrm{~A} \mathrm{~g}^{-1}$, respectively. Energy density (Ed) and power density (Pd) are two important indicators for evaluating the utility of supercapaterry. According to the Ragone plot derived from the GCD curves of the HSC (Fig. 6(g)), the device provides a favorable Ed of $44.6 \mathrm{~W} \mathrm{~h} \mathrm{~kg}^{-1}$ at a Pd of 801.6 $\mathrm{W} \mathrm{kg}-1$, and it maintains an Ed of $18.4 \mathrm{~W} \mathrm{~h} \mathrm{~kg}^{-1}$ even at a high $\mathrm{Pd}$ of $8280.0 \mathrm{~W} \mathrm{~kg}^{-1}$. The Ed values obtained from our device are competitive with similar devices currently reported [42, 48-52]. It is worth noting that $83.9 \%$ of the initial capacity is retained after 10000 cycles at the high current density of $3 \mathrm{~A}$ $\mathrm{g}^{-1}$, suggesting the extraordinary cycle stability of our assembled device (Fig. 6(h)). In addition, the coulombic efficiency is $99.4 \%$ at the end of the cycle test, indicating that the device has high reversibility.

\subsection{Oxygen evolution reaction}

In addition to the above excellent energy storage properties, the prepared M-LDH@PANI-0.5 has good electrocatalytic activity for OER. The electrocatalytic performance is evaluated in 1
M KOH solution using a standard three-electrode system. Fig. 7(a) shows the polarization curves of LDH, M-LDH-x and M-LDH@PANI-0.5 electrocatalysts after IR calibration. The oxidation peak is located at $1.25-1.40 \mathrm{~V}$ (vs. RHE), which may be related to the oxidation of $\mathrm{Ni}^{2+}$ to $\mathrm{Ni}^{3+}[53,54]$. Here, the calculated overpotential of LDH, M-LDH- $x$ and M-LDH@PANI-0.5 based on the linear sweep voltammetry (LSV) polarization curves at the current density of $10 \mathrm{~mA} \mathrm{~cm}^{-2}$ are 323, 311, 301, 286, 289, 308 and $266 \mathrm{mV}$, respectively. The LSV curves of LDH, M-LDH- $x$ and M-LDH@PANI-0.5 electrocatalysts without IR calibration are shown in Fig. S13. The overpotential of LDH, M-LDH- $x$ and M-LDH@PANI-0.5 at the current density of 10 $\mathrm{mA} \mathrm{cm}{ }^{-2}$ are 341, 325, 316, 299, 303, 324 and $277 \mathrm{mV}$, respectively. Besides, the overpotential of the pristine Ni foam (432 $\mathrm{mV})$ and $\mathrm{RuO}_{2}(307 \mathrm{mV})$ are higher than that of M-LDH@PANI-0.5, as shown in Fig. S14(a). The reasons for the improvement of OER performance of the material are as follows: The three-dimensional structure of $\mathrm{Ni}$ foam has high conductivity and a large specific surface area, which can rapidly increase ion/electron transport. The introduction of $\mathrm{MoO}_{4}{ }^{2-}$ can increase the interlayer distance of LDH, affecting the growth order of crystal planes (acicular microspheres into flaky microspheres) in LDH crystals. Moreover, the introduction of $\mathrm{MoO}_{4}{ }^{2-}$ will increase the interlayer distance of $\mathrm{LDH}$, which can improve the number of active sites, the diffusion rate 

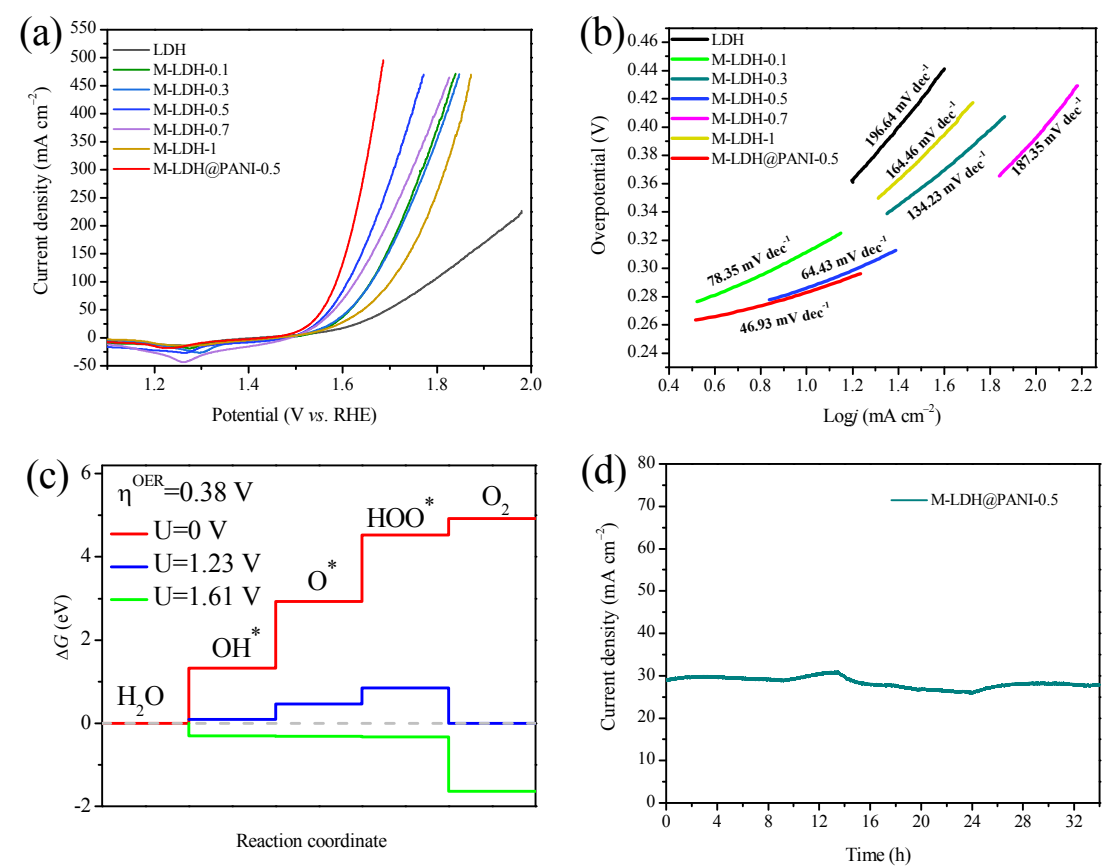

Fig. 7. (a) Polarization curves of LDH, M-LDH- $x$ and M-LDH@PANI-0.5, respectively; (b) Tafel plots of LDH, M-LDH- $x$ and M-LDH@PANI-0.5, respectively; (c) Free energy profiles for the OER over $2 \mathrm{~L} \mathrm{MoO}_{4}{ }^{2-}$ inside $\mathrm{LDH}$ at zero potential $(\mathrm{U}=0)$, equilibrium potential for oxygen evolution $(\mathrm{U}=1.23 \mathrm{~V}$ ) and minimum potential ( $=1.61 \mathrm{~V}$ ) where all steps run downhill; (d) Stability test of M-LDH@PANI-0.5 for $34 \mathrm{~h}$ in $1.0 \mathrm{M} \mathrm{KOH}$.

of $\mathrm{OH}^{-}$and the size of the oxygen-producing space. Besides, the conversion of acicular microspheres (LDH) into flaky microspheres (M-LDH@PANI-0.5) greatly increases the specific surface area, which results in a high contact area between the active materials and the electrolyte. $\mathrm{MoO}_{4}{ }^{2-}$ exists in the form of ions between the LDH layers without participating in the oxygen evolution reaction alone [18,55]: A small amount of $\mathrm{MoO}_{4}{ }^{2-}$ is conducive to the expansion of the interlayer distance of $\mathrm{LDH}$. However, a large number of $\mathrm{MoO}_{4}{ }^{2-}$ could reduce the active sites of $\mathrm{LDH}$ due to the combination of $\mathrm{MoO}_{4}{ }^{2-}$ and $\mathrm{H}$ atoms, causing the attenuation of LDH performance in OER. This is confirmed by the DFT results. Besides, the core-shell structured M-LDH@PANI-0.5 grows directly on Ni foam without conductive additives and polymer binders, reducing dead mass and effectively improving electron transport. The coating of PANI on the surface of M-LDH-0.5 shows the following two advantages: (1) the strong synergistic coupling between M-LDH-0.5 and PANI in M-LDH-0.5@PANI results in electron delocalization between the LDH d-orbitals and the PANI $\pi$-conjugated ligands [14]; (2) the highly conductive PANI with excellent ductility improves the conductivity of LDH, shortens the ion diffusion channel, and enhances the chemical stability of materials [21,23]. Therefore, the introduction of $\mathrm{MoO}_{4}{ }^{2-}$ and the coating of PANI in LDH play key roles in OER. More importantly, the overpotential of M-LDH@PANI-0.5 is lower than that of other non-precious metal electrocatalysts (Table S5). The reaction kinetics of OER is analyzed using the Tafel slope, as shown in Fig. 7(b). The Tafel slope values of LDH, M-LDH- $x$ and M-LDH@PANI-0.5 are 196.64, 78.35, 134.23, 64.43, 187.35, 164.46 and $46.93 \mathrm{mV} \mathrm{dec}^{-1}$, respectively. As displayed in Fig. $\mathrm{S} 14(\mathrm{~b})$, the $R_{s}$ of seven catalysts are similar and about $2 \Omega$. The $R_{c t}$ in low frequency can convey the electrocatalytic kinetics and a lower value corresponds to a faster charge transfer rate. It can be clearly seen that the M-LDH@PANI-0.5 has a smaller Rct than those of other six samples, suggesting faster oxygen evolution rate for OER. To gain further insight on the electrocatalytic activities of these samples, the measurements of electrochemical surface areas (ECSA) are carried out, which can be determined by the electrochemical double-layer capacitance. The linear slope values of LDH, M-LDH- $x$ and M-LDH@PANI-0.5 are $1.58,1.60,2.43,2.83,2.5,1.83$ and $4.4 \mathrm{mF} \mathrm{cm}^{-2}$, respectively, indicating M-LDH@PANI-0.5 can provide more active sites (Fig. S14(c)). These indicate that the increase in the specific surface area, interlayer spacing, and electrical conductivity contributes to the improvement of electrocatalytic performance of the electrode material. The overpotential is determined by the free energies of the reaction intermediates $\mathrm{HO}^{*}, \mathrm{O}^{*}$ and $\mathrm{HOO}^{*}$, which play a crucial role in the rational design of catalysts $[56,57]$. Here, we calculate the free energies of original LDH and two-layer $\mathrm{MoO}_{4}{ }^{2-}$ inside the interface of $\mathrm{LDH}\left(2 \mathrm{~L} \mathrm{MoO}_{4}{ }^{2-}\right.$ inside $\mathrm{LDH}$ ) to show the effect of $\mathrm{MoO}_{4}{ }^{2-}$ intercalation on the OER performance of $\mathrm{LDH}$. The free energies for intermediates $\mathrm{HO}^{*}, \mathrm{O}^{*}, \mathrm{HOO}^{*}$ and calculated overpotentials $(\eta)$ are shown in Table S6. Fig. 7(c) shows the free energies of various intermediates for the OER catalyzed by $2 \mathrm{~L} \mathrm{MoO}_{4}{ }^{2-}$ inside $\mathrm{LDH}$ at different constant potentials. Obviously, all reaction steps are endothermic at zero potential is endothermic. In addition, the first three reaction steps are also endothermic at an equilibrium potential of $1.23 \mathrm{~V}$; until the potential increases to $1.61 \mathrm{~V}$, the free energies for all steps run downhill. These indicate that compared with the equilibrium potential, $\sim 0.38 \mathrm{~V}$ overpotential is needed for the OER process on $2 \mathrm{~L} \mathrm{MoO}_{4}{ }^{2-}$ inside $\mathrm{LDH}$, while the overpotential of the original LDH is $0.76 \mathrm{~V}$. The increase of OER activity of $\mathrm{MoO}_{4}{ }^{2-}$ modified $\mathrm{LDH}$ is due to the 
charge redistribution caused by the binding of $\mathrm{MoO}_{4}{ }^{2-}$ on the surface and the exposure of more active sites due to the expansion of LDH interlayer spacing, which can improve the diffusion rate of $\mathrm{OH}^{-}$and the size of the oxygen-producing space. Stability is also critical to the application of the catalyst in energy conversion systems. Therefore, the catalytic stability of M-LDH@PANI-0.5 is investigated at the overpotential of 307 $\mathrm{mV}$ to reach a constant current density of $30 \mathrm{~mA} \mathrm{~cm}^{-2}$, as displayed in Fig. 7(d). It is found that M-LDH@PANI-0.5 has excellent catalytic stability and supplies a very stable voltage for the duration of $34 \mathrm{~h}$ with minimal changes. Fig. S14(d) shows the XPS spectra of N1s before and after stability tests of M-LDH@PANI-0.5 for 34 h. After long-term OER test, the peak intensity of $\mathrm{N} 1 s$ is obviously weakened, which reveals that polyaniline is easily oxidized during the water oxidation condition. To evaluate the practical applicability of the prepared material, we successfully illuminate green LED bulbs and disassemble the $1 \mathrm{M} \mathrm{KOH}$ solution into hydrogen and oxygen using the assembled HSC as the energy source and M-LDH@PANI as the catalyst (Fig. S15).

\section{Conclusions}

In summary, we have demonstrated a strategy to improve the electrochemical performance of $\mathrm{LDH}$ by introducing $\mathrm{MoO}_{4}{ }^{2-}$ into the layers of NiCo-LDH coated with PANI. Both experimental and theoretical studies reveal insight into the significant effect of the incorporation of $\mathrm{MoO}_{4}{ }^{2-}$ on the structure and properties of M-LDH. Importantly, the intercalation of an appropriate amount of $\mathrm{MoO}_{4}{ }^{2-}$ into $\mathrm{LDH}$ regulates the deprotonation energy, while excess $\mathrm{MoO}_{4}{ }^{2-}$ inhibit the reaction of $\mathrm{OH}^{-}$ and $\mathrm{H}$ atoms, hindering energy storage and OER processes. The as-obtained M-LDH@PANI-0.5 exhibits a superior electrocatalytic activity for oxygen evolution reaction (a small overpotential of $266 \mathrm{mV}$ at $10 \mathrm{~mA} \mathrm{~cm}-2$ ), and a high charge storage capability of $864.8 \mathrm{C} \mathrm{g}^{-1}$ for use as electrodes for supercapaterry. A supercapaterry with the M-LDH@PANI-0.5 composite electrode shows high energy density of $44.6 \mathrm{Wh} \mathrm{kg}^{-1}$, an improved power density ( $8300.0 \mathrm{~W} \mathrm{~kg}^{-1}$ ), and unwavering cyclic stability (10000 cycles). The results indicate that the rational design of the interlayer space of layered transition metal hydroxides is significant for improving the energy storage and catalytic ability of materials, which provides a theoretical guidance for exploring the relationship between the microstructure, morphology, and electrochemical performance of materials.

\section{Electronic supporting information}

Supporting information is available in the online version of this article.

\section{References}

[1] Y. Guo, Ya. Chen, H. Cui, Z. Zhou, Chin. J. Catal., 2019, 40, 1298-1310.

[2] S. Song, J. Zhou, J. Sun, S. Zhang, X. Lin, Z. Hu, J. Hu, L. Zhang, J. Wang, Chin. J. Catal., 2020, 41, 592-597.

[3] C. Jing, X. Liu, K. Li, X. Liu, B. Dong, F. Dong, Y. Zhang, J. Energy Chem., 2021, 52, 218-227.

[4] J. Xing, F. Lin, L. Huang, Y. Si, Y. Wang, L. Jiao, Chin. J. Catal., 2019, 40, 1352-1359.

[5] Q. Hu, X. Jiang, M. He, Q. Zheng, K.H. Lam, D. Lin, Electrochim. Acta, 2020, 338, 135896.

[6] X. Wei, B. Zhang, M. Liao, P. Xiao, X. Zhou, Y. Zhang, J. Liu, J. Mater. Chem. A, 2020, 8, 17248-17256.

[7] H. Wang, H. Yuan, X. Li, F. Zeng, K. Wu, Q. Zheng, G. Fan, D. Lin, Chem. Eng.J., 2020, 394, 124879.

[8] Q. Hu, M. Tang, M. He, N. Jiang, C. Xu, D. Lin, Q. Zheng, J. Power Sources, 2020, 446, 227335.

[9] C. Jing, X. Song, K. Li, Y. Zhang, X. Liu, B. Dong, F. Dong, S. Zhao, H. Yao, Y. Zhang, J. Mater. Chem. A, 2020, 8, 1697-1708.

[10] W. Sun, Y. Du, G. Wu, G. Gao, H. Zhu, J. Shen, K. Zhang, G. Cao, J. Mater. Chem. A, 2019, 7, 7138-7150.

\section{Graphical Abstract}

Chin. J. Catal., 2021, 42: 980-993 doi: 10.1016/S1872-2067(20)63724-X

\section{Critical roles of molybdate anions in enhancing capacitive and oxygen evolution behaviors of LDH@PANI nanohybrids}

Qiang Hu, Hua Wang, Feifei Xiang, Qiaoji Zheng, Xinguo Ma, Yu Huo, Fengyu Xie, Chenggang Xu, Dunmin Lin*, Jisong Hu* Sichuan Normal University; Hubei University of Technology

A polyaniline-coated NiCo layered double hydroxide intercalated with $\mathrm{MoO}_{4}{ }^{2-}$ (M-LDH@PANI) composite electrode is used in high-performance supercapaterry and oxygen evolution reactions.

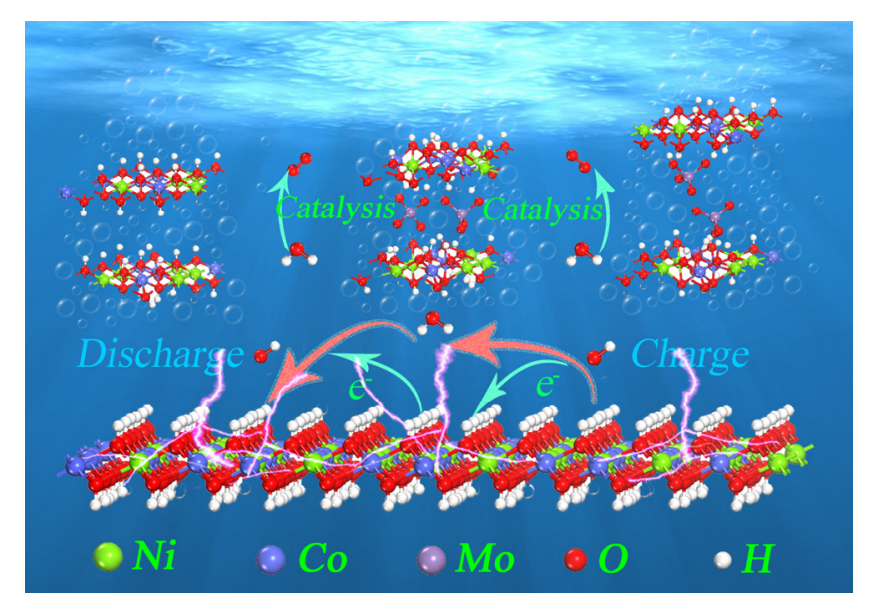


[11] H. Jin, J. Wang, D. Su, Z. Wei, Z. Pang, Y. Wang, J. Am. Chem. Soc., 2015, 137, 2688-2694.

[12] H. Jin, S. Mao, G. Zhan, F. Xu, X. Bao, Y. Wang, J. Mater. Chem. A, 2017, 5, 1078-1084.

[13] X. Li, X. Hao, Z. Wang, A. Abudula, G. Guan, J. Power Sources, 2017, $347,193-200$.

[14] J. X. Feng, L. X. Ding, S. H. Ye, X. J. He, H. Xu, Y. X. Tong, G. R. Li, Adv. Mater., 2015, 27, 7051-7057.

[15] H. Wu, Y. Zhang, W. Yuan, Y. Zhao, S. Luo, X. Yuan, L. Zheng, L. Cheng, J. Mater. Chem. A, 2018, 6, 16617-16626.

[16] R. Chen, S. F. Hung, D. Zhou, J. Gao, C. Yang, H. Tao, H. B. Yang, L. Zhang, L. Zhang, Q. Xiong, H. M. Chen, B. Liu, Adv. Mater., 2019, 1903909.

[17] M. Luo, Z. Cai, C. Wang, Y. Bi, L. Qian, Y. Hao, L. Li, Y. Kuang, Y. Li, X. Lei, Z. Huo, W. Liu, H. Wang, X. Sun, X. Duan, Nano Res., 2017, 10, 1732-1739.

[18] L. Wang, Z. H. Dong, Z. G. Wang, F. X. Zhang, J. Jin, Adv. Funct. Mater., 2013, 23, 2758-2764.

[19] R. L. Frost, A. W. Musumeci, W. N. Martens, M. O. Adebajo, J. Bouzaid, J. Raman Spectrosc., 2005, 36, 925-931.

[20] X. Gao, X. Liu, D. Wu, B. Qian, Z. Kou, Z. Pan, Y. Pang, L. Miao, J. Wang, Adv. Funct. Mater., 2019, 29, 1903879.

[21] J. Zhu, W. Sun, D. Yang, Y. Zhang, H. H. Hoon, H. Zhang, Q. Yan, Small, 2015, 11, 4123-4129.

[22] L. Li, Z. Lou, W. Han, D. Chen, K. Jiang, G. Shen, Adv. Mater. Technol., 2017, 2, 1600282.

[23] L. Xiao, Y. Cao, J. Xiao, B. Schwenzer, M. H. Engelhard, L. V. Saraf, Z. Nie, G. J. Exarhos, J. Liu, Adv. Mater., 2012, 24, 1176-1181.

[24] Z. Liu, R. Ma, M. Osada, K. Takada, T. Sasaki, J. Am. Chem. Soc., 2005, 127, 13869-13874.

[25] L. Xie, Z. Hu, C. Lv, G. Sun, J. Wang, Y. Li, H. He, J. Wang, K. Li, Electrochim. Acta, 2012, 78, 205-211.

[26] A. M. Bernhard, D. Peitz, M. Elsener, A. Wokaun, O. Kröcher, Appl. Catal. B, 2012, 115, 129-137.

[27] M. Prabhaharan, A. R. Prabakaran, S. Srinivasan, S. Gunasekaran, Spectrochim. Acta A, 2015, 138, 711-722.

[28] X. Ruan, Y. Chen, H. Chen, G. Qian, R. L. Frost, Chem. Eng. J., 2016, 297, 295-303.

[29] J. Fang, M. Li, Q. Li, W. Zhang, Q. Shou, F. Liu, X. Zhang, J. Cheng, Electrochim. Acta, 2012, 85, 248-255.

[30] K. H. Ho, H. J. Liu, Q. Q. Ke, L. Mao, Y. T. Hu, X. Li, J. Wang, J. Am. Ceram. Soc., 2017, 100, 247-256.

[31] X. Li, Z. Yang, W. Qi, Y. Li, Y. Wu, S. Zhou, S. Huang, J. Wei, H. Li, P. Yao, Appl. Surf. Sci., 2016, 363, 381-388.

[32] X. Bai, Q. Liu, J. Liu, Z. Gao, H. Zhang, R. Chen, Z. Li, R. Li, P. Liu, J. Wang, Chem. Eng. J., 2017, 328, 873-883.

[33] S. Liu, Y. Yin, D. X. Ni, K. S. Hui, K. N. Hui, S. Lee, C.-Y. Ouyang, S. C.
Jun, Energy Storage Mater., 2019, 19, 186-196.

[34] H. Liang, J. Lin, H. Jia, S. Chen, J. Qi, J. Cao, T. Lin, W. Fei, J. Feng, J. Mater. Chem. A, 2018, 6, 15040-15046.

[35] J. Lin, H. Jia, H. Liang, S. Chen, Y. Cai, J. Qi, J. Cao, W. Fei, J. Feng, C. Qu, Adv. Sci., 2018, 5, 1700687.

[36] X. Wei, Y. Li, H. Peng, D. Gao, Y. Ou, Y. Yang, J. Hu, Y. Zhang, P. Xiao, Chem. Eng. J., 2019, 355, 336-340.

[37] X. Liu, Z. Wu, Y. Yin, Chem. Eng. J., 2017, 323, 330-339.

[38] Z. Song, X. Lu, Q. Hu, J. Ren, W. Zhang, Q. Zheng, D. Lin, J. Power Sources, 2019, 421, 23-31.

[39] W. Sun, G. Gao, Y. Du, K. Zhang, G. Wu, J. Mater. Chem. A, 2018, 6, 9938-9947.

[40] S. Liu, Y. Yin, D. X. Ni, K. S. Hui, M. Ma, S. Park, K. N. Hui, C.-Y. Ouyang, S. C. Jun, Energy Storage Mater., 2019, 22, 384-396.

[41] J. Yang, C. Yu, X. Fan, Z. Ling, J. Qiu, Y. Gogotsi, J. Mater. Chem. A, 2013, 1, 1963-1968.

[42] Z. Xiao, Y. Mei, S. Yuan, H. Mei, B. Xu, Y. Bao, L. Fan, W. Kang, F. Dai, R. Wang, L. Wang, S. Hu, D. Sun, H. C. Zhou, ACS Nano, 2019, 13, 7024-7030.

[43] Y. Wang, H. Dou, J. Wang, B. Ding, Y. Xu, Z. Chang, X. Hao, J. Power Sources, 2016, 327, 221-228.

[44] Y. Lan, M. Li, W. Fan, Q. Deng, Z. Zeng, J. Wang, S. Deng, Electrochim. Acta, 2019, 321, 134708.

[45] Y. Liu, X. Teng, Y. Mi, Z. Chen, J. Mater. Chem. A, 2017, 5, 24407-24415.

[46] J. Yang, C. Yu, C. Hu, M. Wang, S. Li, H. Huang, K. Bustillo, X. Han, C. Zhao, W. Guo, Z. Zeng, H. Zheng, J. Qiu, Adv. Funct. Mater., 2018, 28, 1803272.

[47] Y. Guo, X. Hong, Y. Wang, Q. Li, J. Meng, R. Dai, X. Liu, L. He, L. Mai, Adv. Funct. Mater., 2019, 29, 1809004.

[48] L. Yu, N. Shi, Q. Liu, J. Wang, B. Yang, B. Wang, H. Yan, Y. Sun, X. Jing, Phys. Chem. Chem. Phys., 2014, 16, 17936-17942.

[49] D. Zhao, H. Liu, X. Wu, Nano Energy, 2019, 57, 363-370.

[50] X. Ge, C. Gu, Z. Yin, X. Wang, J. Tu, J. Li, Nano Energy, 2016, 20, 185-193.

[51] M. Yu, R. Liu, J. Liu, S. Li, Y. Ma, Small, 2017, 13, 1702616.

[52] X. Hao, Z. Jiang, X. Tian, X. Hao, Z. Jiang, Electrochim. Acta, 2017, 253, 21-30.

[53] R. D. Senthil, X. F. Chuah, C. T. Hsieh, Y. A. Chen, S. Y. Lu, Appl. Catal. $B, \mathbf{2 0 1 9}, 258,118023$.

[54] J. Liang, Y. Z. Wang, C. C. Wang, S. Y. Lu, J. Mater. Chem. A, 2016, 4, 9797-9806.

[55] N. Han, F. Zhao, Y. Li, J. Mater. Chem. A, 2015, 3, 16348-16353.

[56] Y. Duan, Z. Y. Yu, S. J. Hu, X. S. Zheng, C. T. Zhang, H. H. Ding, B. C. Hu, Q. Q. Fu, Z. L. Yu, X. Zheng, J. F. Zhu, M. R. Gao, S. H. Yu, Angew. Chem. Int. Ed., 2019, 58, 15772-15777.

[57] X. Cui, P. Ren, D. Deng, J. Deng, X. Bao, Energy Environ. Sci., 2016, 9, 123-129.

\title{
钼酸根阴离子在增强聚苯胺包覆的镍钴层状氢氧化物的电容和析氧行为 中的关键作用
}

\author{
胡 强 ${ }^{\mathrm{a}}$, 王 华 ${ }^{\mathrm{a}}$, 向飞菲 ${ }^{\mathrm{a}}$, 郑养佶 ${ }^{\mathrm{a}}$, 马新国 ${ }^{\mathrm{b}}$, 霍 瑜 ${ }^{\mathrm{a}}$, 谢奉妤 ${ }^{\mathrm{a}}$, 徐成刚 ${ }^{\mathrm{a}}$, 赁敦敏 ${ }^{\mathrm{a},{ }^{*}}$, 胡吉松 ${ }^{\mathrm{b}, \#}$ \\ ${ }^{\mathrm{a}}$ 四川师范大学化学与材料科学学院, 四川成都610066

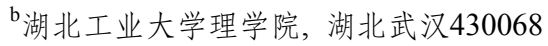

摘要: 理论容量大且过电位低的层状氢氧化物(LDHs) 是极有前景的超级电容电池和析氧反应的电极材料; 然而, 体相 LDHs的低电导率和活性位点不足增加了电极的内阻, 降低了电极容量和产氧效率. 本文采用两步法制备了聚苯胺包覆的 $\mathrm{MoO}_{4}{ }^{2-}$ 插层的镍钴层状双金属氢氧化物复合电极(M-LDH@PANI). 随着 $L D H$ 中 $\mathrm{MoO}_{4}{ }^{2-}$ 含量的增加, 针状的LDH微球逐渐 
演化为具有较高比表面积的片状M-LDH微球, 这为整个电极提供了更多的电化学位点. 此外, 非晶态的聚苯胺包覆提高了 复合电极的电导率. 在引入适量 $\mathrm{MoO}_{4}{ }^{2-}$ 插层离子时, M-LDH@PANI表现出显著强化的储能和催化性能. 所获得的 M-LDH@PANI-0.5在析氧反应中表现出优越的电催化活性 $(10 \mathrm{~mA} \mathrm{~cm}$ 时的过电位为 $266 \mathrm{mV})$, 作为超级电容电池电极则 具有 $864.8 \mathrm{C} \mathrm{g}^{-1}$ 的高容量. 采用 M-LDH@PANI- 0.5 作为正极及以活性炭作为负极组装的超级电容电池在功率密度为 $8,300.0 \mathrm{~W} \mathrm{~kg}^{-1}$ 时能量密度为 $44.6 \mathrm{Wh} \mathrm{kg}^{-1}$, 且具有优异的循环稳定性(10000次循环后保留 $83.9 \%$ 的初始容量). 本文为 $\mathrm{LDH}$ 基材料的阴离子插层改性增强材料性能的机理提供了一个非传统的解释. 在上述研究基础上,采用射线衍射(XRD)、X射 线光电子能谱(XPS)、扫描电子显微镜(SEM)、高分辨透射电镜(HRTEM)和比表面积测试(BET)等手段对样品进行了深入 表征.

$\mathrm{XRD}$ 结果表明, $\mathrm{MoO}_{4}{ }^{2-}$ 插层的 $\mathrm{LDH}$ 材料的层间晶面(003)的峰随着 $\mathrm{MoO}_{4}{ }^{2-}$ 含量的增加而逐渐消失, 这是由于晶面间距 越大越容易受到晶粒细化的影响, 间距大的晶格更容易受到破坏, 导致晶格的展宽和弱化, 从而间接证明 $\mathrm{MoO}_{4}{ }^{2-}$ 的成功插 层. SEM、HRTEM和BET测试结果表明, $\mathrm{MoO}_{4}{ }^{2-}$ 的含量对材料的形貌和比表面积具有重大影响. 利用XPS对样品的价态进 行了研究, 发现随着 $\mathrm{MoO}_{4}{ }^{2-}$ 含量的增加, $\mathrm{Co}$ 和 $\mathrm{Ni}$ 的价态没有明显变化. 电化学测试结果表明, 电极的储能和催化性能随 $\mathrm{MoO}_{4}{ }^{2-}$ 含量的增加而先增加后减小. 利用理论计算分析了 $\mathrm{MoO}_{4}{ }^{2-}$ 在 $\mathrm{LDH}$ 中的插层行为, 发现少量的 $\mathrm{MoO}_{4}{ }^{2-}$ 有利于扩大 $\mathrm{LDH}$ 的层间间距, 而过量的 $\mathrm{MoO}_{4}{ }^{2-}$ 则会与 $\mathrm{LDH}$ 的 $\mathrm{H}$ 原子结合, 从而与电解液中的 $\mathrm{OH}^{-}$竞争, 导致复合电极的电化学性能下 降. 此外, $\mathrm{MoO}_{4}{ }^{2-}$ 插层的片状微球能有效调节材料的去质子化能, 大大加速电极表面的氧化还原反应. 因此, $\mathrm{MoO}_{4}{ }^{2-}$ 插层能 够显著强化LDH基材料的超级电容电池电极和OER催化剂电化学性能.

关键词: 层状氢氧化物; 聚苯胺; 钿酸根离子; 插层分级结构; 超级电容电池; 电催化剂

收稿日期: 2020-08-17. 接受日期: 2020-10-09. 上网日期: 2020-11-22.

*通讯联系人. 电话/传真: (028)84760802; 电子信箱: ddmd222@sicnu.edu.cn

\#通讯联系人. 电子信箱: jisong.hu@yahoo.com

基金来源: 四川省科学技术计划(2018JY0447).

本文的电子版全文由Elsevier出版社在ScienceDirect上出版(http://www.sciencedirect.com/science/journal/18722067). 